\title{
Mean Flow and Variability in the Kuroshio Extension From Geosat Altimetry Data
}

\author{
Bo QIU, Kathryn A. Kelly and Terrence M. Joyce \\ Woods Hole Oceanographic Institution, Woods Hole, Massachusetts
}

\begin{abstract}
Using altimeter data from the Geosat Exact Repeat Mission (ERM), we investigated the mean flow and temporal and spatial variations of the Kuroshio Extension in the region of $140^{\circ}-180^{\circ} \mathrm{E}$ and $30^{\circ}-40^{\circ} \mathrm{N}$. Mean surface height profiles were estimated along individual tracks by assuming the velocity profile of the Kuroshio Extension to be Gaussian-shaped and by successively fitting this synthetic current's height profile to the residual height data. Using the mean profiles from ascending and descending tracks, we derived the mean surface height field by an inverse method and obtained the absolute surface height fields for the first 2.5 years of the Geosat ERM. Both the mean and the instantaneous height fields thus derived compared well with the available hydrographic data and the SST patterns from the NOAA satellites. The mean surface height difference across the Kuroshio Extension attains its maximum around $146^{\circ} \mathrm{E}$ between the two quasi-stationary meanders, and its decrease thereafter is mainly due to large-scale recirculations on the southern side of the Kuroshio Extension. The ratio of the eddy kinetic energy over the mean kinetic energy has a nearly constant value of 1.5-2.0 along the Kuroshio Extension path. Propagation of mesoscale fluctuations in the height fields is generally westward except for the upstream region of the Kuroshio Extension. Effects of deep mean flow and baroclinic shear are found to be important in explaining the observed propagation speeds. In the upstream region of $141^{\circ} \mathrm{E}$ and $154^{\circ} \mathrm{E}$, annual variations in the surface height difference across the Kuroshio Extension $(\delta h)$ have a September maximum with an average amplitude of $0.2 \mathrm{~m}$. For large-scale interannual fluctuations, anomalies in $\delta h$ are found to be significantly correlated with those of the current axis positions: a larger surface height difference corresponds to a more northerly position of the Kuroshio Extension. The interannual changes in $\delta h$ are possibly related to the $86 / 87$ ENSO event in the low-latitude Pacific Ocean.
\end{abstract}

\section{INTRODUCTION}

The Kuroshio enters the open basin of the North Pacific after separating from the southern coast of Japan at $140^{\circ} \mathrm{E}$ and $35^{\circ} \mathrm{N}$. Thereafter, it is named the Kuroshio Extension [Kawai, 1972]. Like the Gulf Stream after Cape Hatteras in the North Atlantic, the Kuroshio Extension is characterized as an eastward flowing inertial jet accompanied by largeamplitude meanders and vigorons pinched-off eddies.

During the past decade, a number of investigators have explored the variability of the Kuroshio Extension from various viewpoints. On the basis of water temperature measurements at $300 \mathrm{~m}$ depth, Bernstein and White [1981] and Mizuno and White [1983] studied the temporal and spatial variations of the temperature front of the Kuroshio Extension. They investigated in detail the westward propagation of the mesoscale perturbations $(200-600 \mathrm{~km})$ and the influence of the bathymetric features on the frontal meanders. Interannual variability was also found to be prominent in the Kuroshio Extension [Mizuno and White, 1983]. Direct current measurements, accompanied by conductivitytemperature-depth (CTD) observations, were performed intensively from 1980 to 1985 across the Kuroshio Extension along meridians of $152^{\circ} \mathrm{E}$ [Schmitz et al., 1982, 1987; Niiler, et al., 1985], $165^{\circ} \mathrm{E}$, and $175^{\circ} \mathrm{W}$ [Joyce, 1987; Schmitz, 1988; Joyce and Schmitz, 1988]. These measurements revealed the existence of steady westward deep flows $\left(\sim 2 \mathrm{~cm} \mathrm{~s}^{-1}\right)$ and the baroclinic volume transport of the Kuroshio Extension

Copyright 1991 by the American Geophysical Union.

Paper number 91JC01834.

0148-0277/91/91 JC-01834\$05.00 $\left(57 \mathrm{~Sv}\right.$ at $152^{\circ} \mathrm{E}, 56 \pm 2 \mathrm{~Sv}$ at $165^{\circ} \mathrm{E}$, and $22 \pm 3 \mathrm{~Sv}$ at $175^{\circ} \mathrm{W}$ ), as well as the energetics of the current along these meridians. Some of the mooring results were further compared with numerical studies and with the mooring results from the Gulf Stream [Schmitz and Holland, 1986; Hall, 1989, 1991]. In particular, Hall [1989] noticed that the Kuroshio Extension has a larger relative barotropic component than the Gulf Stream. In the region of the Kuroshio Extension near the east coast of Japan, many studies have focused on the warmcore rings and their interactions with the Kuroshio Extension ' Kawai, 1972; Kawai and Saitoh, 1986; Kawamura et al., 1986; Yasuda et al., 1991].

Although our knowledge of the variability of the Kuroshio Extension has increased steadily over the past decade, understanding of the entire Kuroshio Extension region, especially in terms of its velocity fields, remains far from satisfactory. This is primarily due to the vast geographical extent of the current system as well as limitations in existing measurement techniques. The Exact Repeat Mission (ERM) of Geosat, with its global coverage over a period of 3 years, provided a new means to investigate the mean circulation and variability of the surface velocity in the Kuroshio Extension. Like other satellite-borne radar altimeters, the Geosat altimeter measures the distance from the satellite to the sea surface which, when combined with the satellite position and the Earth's gravity field (the geoid), yields the sea surface height field that can be used to infer the surface geostrophic velocity field [e.g., Wunsch and Gaposchkin, 1980]. One problem in extracting surface velocity from the altimetry data, however, is that the geoid, which has geographical height variations much larger than those of the oceans, is not known on length scales of a few hundred kilometers [Marsh and Chang, 1984; Imawaki et al., 1991]. Un- 
fortunately, this is the scale of the ocean current in which we are most interested. Lack of geoid information, in fact, has limited most studies based on altimetry data to focus on either the residual components of the sea surface height or the basin-scale circulation pattern [e.g., Tai and Wunsch, 1984].

Recently, Kelly and Gille [1990] solved this problem using a synthetic method that estimates the mean height profile along subtracks from the residual height data. Their results for the Gulf Stream along an ascending subtrack between Cape Cod and Bermuda were found to be in remarkable agreement with the sea surface height profile based on acoustic Doppler current profiler (ADCP) and expendable bathythermograph (XBT) measurements [Kelly et al., 1991]. By using this method, Kelly [1991] has recently studied the velocity statistics of the Gulf Stream in the region between $73^{\circ} \mathrm{W}$ and $46^{\circ} \mathrm{W}$. She found that at low frequencies the position and the surface velocity of the Gulf Stream were highly correlated, with larger surface transport leading more northerly positions. An approach similar to that of Kelly and Gille [1990] was recently proposed by Tai [1990], who compared the surface transport between the Gulf Stream and the Kuroshio Extension and discussed the seasonal cycles in the two streams.

In the present study we modified the synthetic method of Kelly and Gille to determine the two-dimensional mean sea surface height field for the Kuroshio Extension region. The determination of the mean sea surface height field was based on both the descending and ascending residual height data, and the arbitrary offsets of the mean height profiles along subtracks were removed using an inverse method. The mean sea surface height field thus derived is shown to agree well with the sea surface dynamic height field from conventional dynamical calculations. Obtaining the mean sea surface height field allows us to estimate the absolute sea surface height in the Kuroshio Extension region for the first 2.5 years of the Geosat ERM. Using this data set of absolute sea surface height fields, we studied in detail the mean circulation pattern in the Kuroshio Extension region, the mean and eddy kinetic energy distributions, and the temporal and spatial variations of the surface height fluctuations associated with the Kuroshio Extension and its neighboring fields. The annual variations in the surface height difference across the Kuroshio Extension and the relationship between the current axis position and the surface height difference were also investigated.

Since the present study was based on a new treatment of Geosat data, the first few sections of the paper concentrate on the methodology. For readers who are more interested in the physical results of the Kuroshio Extension, we recommend starting from the discussion of Figure 3 in the second half of section 4. Results in later sections can be read and largely understood without background in the methodology.

\section{Processing the Geosat Data}

The first 54 repeat cycles of the Geosat altimeter height data, from November 1986 through April 1989, were used in the present study. To focus on the Kuroshio Extension region, all ascending and descending subtracks between $140^{\circ} \mathrm{E}$ and $180^{\circ}$ were processed (see Figure 1).

For each of the 54 selected subtracks, the raw altimeter height data from $20^{\circ} \mathrm{N}$ to $50^{\circ} \mathrm{N}$ were first adjusted for

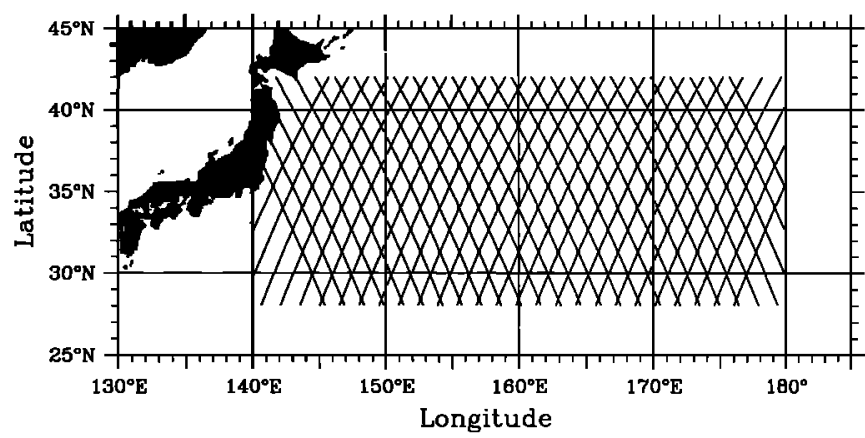

Fig. 1. Distributions of ascending and descending subtracks of the Geosat ERM in the region $30^{\circ}-40^{\circ} \mathrm{N}$ and $140^{\circ}-180^{\circ} \mathrm{E}$.

tides, water vapor (Fleet Numerical Oceanographic Center), tropospheric and ionospheric delays, and surface pressure according to correction factors provided on the $\mathrm{Na}$ tional Oceanographic Data Center distribution tapes [Cheney et al., 1987]. The data were then edited to remove obvious anomalous points and interpolated to a common latitude-longitude grid with an alongtrack resolution of $0.98 \mathrm{~s}(6.6 \mathrm{~km})$. Since the orbital errors in the measured height data were dominated by the components having a frequency of one cycle per satellite revolution, these errors were removed by fitting the height profile to a sinusoid with a period of $6064 \mathrm{~s}$ (the Geosat orbital period). The least squares fit to the sinusoid was weighted by the inverse of the height variance to prevent mesoscale height variations due to currents and the geoid from biasing the orbit correction [Caruso et al., 1990]. The residual height profiles were calculated by subtracting from each corrected height profile the temporally averaged profile (namely, the geoid plus the mean sea surface height). Throughout this paper, the term "residual" denotes a quantity that deviates from its temporal mean. For estimating the cross-track velocity component, which is proportional to the height gradient using the geostrophic approximation, the residual height data were low-pass filtered to eliminate small-scale instrument errors. For lack of direct comparison with measurements in the Kuroshio Extension, we used the same low-pass filter as Kelly and Gille [1990] used for the Gulf Stream: it has a half power point at $76 \mathrm{~km}$ and was determined by maximizing the covariance between the Geosat data and the in-situ ADCP measurements [Joyce et al., 1990].

\section{Synthetic Method and Modification}

The basis of Kelly and Gille's synthetic method is that along a subtrack across a jet, the large lateral excursions of the jet cause the mean surface height profile to have a more gradual slope than the instantaneous height profiles. If the instantaneous cross-stream velocity profile is assumed to have a Gaussian form,

$$
u_{s}(y)=a_{1} \exp \left[\frac{-\left(y-a_{2}\right)^{2}}{2 a_{3}^{2}}\right]
$$

the distinction between the mean height profile and the instantaneous height profile enables one to estimate a time series of $a_{2}$ and $a_{3}$ values from individual residual height profiles $h^{\prime}(y)$, where $a_{2}$ is the center position of the jet, and $a_{3}$ is the width parameter. For each pair of $a_{2}$ and $a_{3}$, a synthetic height profile $h_{s}$ relative to some reference level is given by 


$$
\begin{aligned}
h_{\cdot}(y) & =-\frac{f}{g} \int^{y} u_{s}\left(y^{\prime}\right) d y^{\prime} \\
& =-\frac{f}{g} a_{1} a_{3} \sqrt{\pi / 2} \operatorname{erf}\left(\frac{y-a_{2}}{\sqrt{2} a_{3}}\right)
\end{aligned}
$$

where $\operatorname{erf}(y)$ is the error function. By setting $a_{1}$, the velocity maximum, to some initial guess, one can obtain a synthetic mean height profile $\left\langle h_{0}\right\rangle$ by simply averaging the synthetic height profiles from all the cycles. New $a_{i}$ are estimated by least squares fits of the individual synthetic height profiles to the residual height data plus the synthetic mean height to minimize

$$
\sum_{y}\left[h^{\prime}+<h_{s}>+\gamma-h_{s}\right]^{2}
$$

where $\gamma$ is a constant offset to account for uncorrected orbit errors. The least squares fit (equation (3)) is then iterated for each cycle to improve the estimates of $a_{i}$, until $\left\langle h_{s}\right\rangle$ converges.

Notice that the assumption that a Gaussian-shaped velocity profile is appropriate for the Gulf Stream is supported by both the ADCP measurements [Joyce et al., 1986] and subsurface moorings [Hall and Bryden, 1985]. Comparative studies of the Gulf Stream and the Kuroshio Extension by Hall [1989] showed that such a velocity profile is also a good approximation for the surface Kuroshio Extension at $152^{\circ} \mathrm{E}$. Although the CTD observations across the Kuroshio Extension farther downstream along $165^{\circ} \mathrm{E}$ and $175^{\circ} \mathrm{W}$ are too sparse in space to determine the detailed surface velocity structure, well-defined jets associated with the Kuroshio Extension can be clearly seen in the results of Joyce [1987].
One practical problem in applying the synthetic method to the Kuroshio Extension and the Gulf Stream is that frequently, several velocity maxima appear in the residual velocity profiles, which makes the initial guess of $a_{2}$ difficult. Physically, this is due to multiple crossings of the jet near large-amplitude meanders and nearby warm-core and cold-core rings. As in the Gulf Stream, the velocity peak associated with the Kuroshio Extension is usually obvious from the location and the magnitude of the residual velocity peaks. There are, however, cases where ambiguity remains, such as when warm-core and cold-core rings are strong or are about to be pinched off. Comparing the residual velocity profiles along both ascending and descending subtracks was found useful in solving some of these problems. Also found useful in determining which the velocity peaks corresponded to the Kuroshio Extension was to compare the residual profiles with those of the previous and subsequent cycles. This is because the temporal decorrelation scale for the residual velocities in the Kuroshio Extension region is on average 75 days or 4.5 cycles. In terms of sampling resolution, this scale is double that of the spatial decorrelation, which is $230 \mathrm{~km}$ or 2.5 subtracks for the same region (compare the decorrelation scales in the residual height data shown in Figure 5a).

Another practical problem concerning the synthetic method here is the nonlinear dependency on the parameters $a_{i}$ in the least squares fit of (3). Kelly and Gille [1990] performed the fitting by adjusting $a_{1}$ and $a_{2}$ separately and keeping $a_{3}$ unchanged from its initial estimate. In the present study we performed the nonlinear least squares fit by adopting the Levenberg-Marquardt method [Press et al., 1986]. This method adjusts the $a_{i}$ values in the least
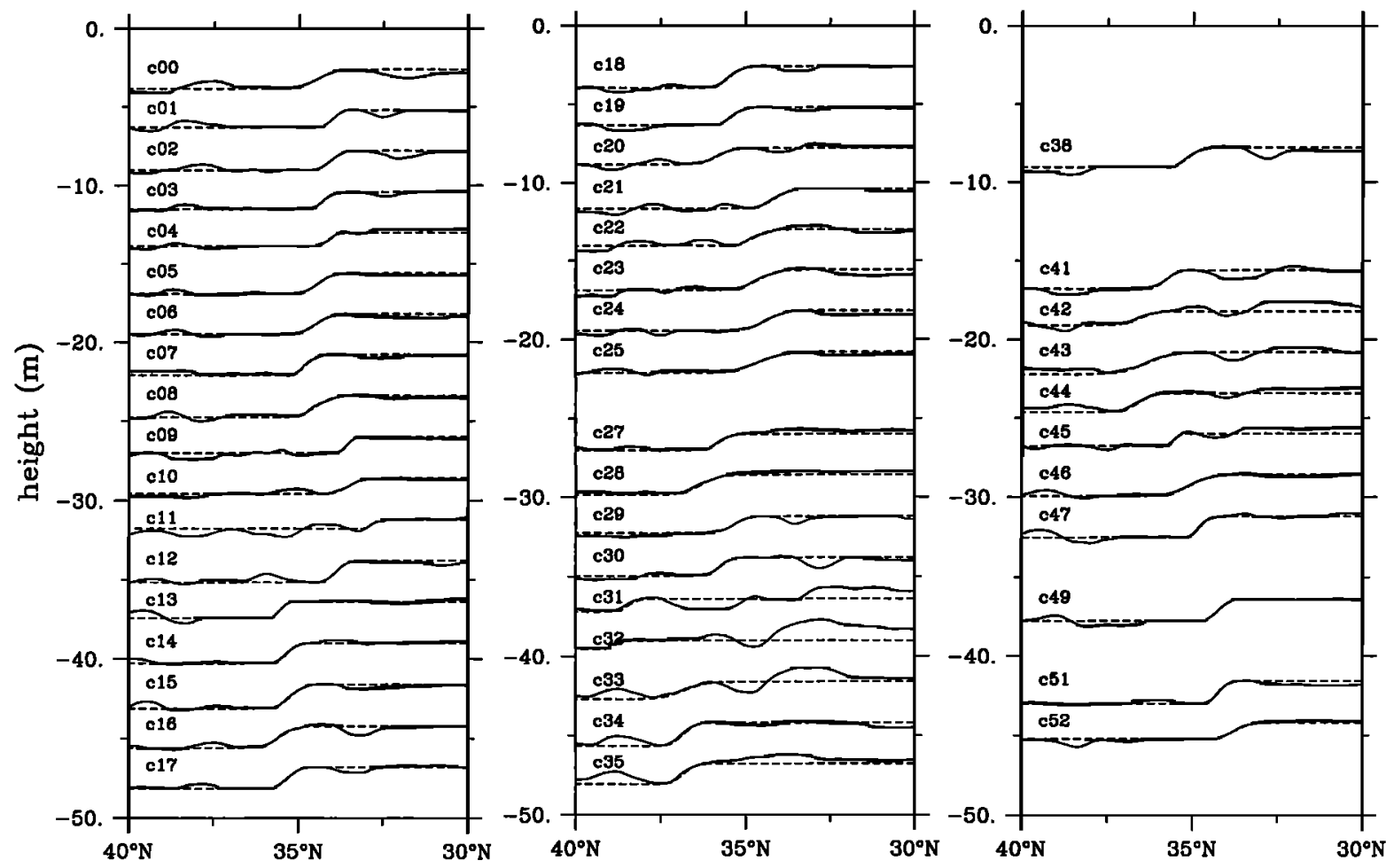

Fig. 2. Synthetic height profiles (dashed lines) and the profiles of the residual height plus the synthetic mean height (solid lines) for the ascending subtrack a180. Numbers in the upper left corners of each profile indicate the ERM cycles and the profiles for each cycle are shown with an offset of $2.6 \mathrm{~m}$. 
squares fit (3) simultaneously. The Levenberg-Marquardt method would be particularly helpful if one were to apply the synthetic method to a more complicated mean velocity field, for example, the Kuroshio region south of Japan where the velocity field commonly consists of the Kuroshio and a quasi-stationary large cold water mass [Kawabe, 1985].

As an example, we show in Figure 2 the results of synthetic height profiles for the ascending subtrack a180 (which passes the point $35^{\circ} \mathrm{N}, 146^{\circ} \mathrm{E}$ ) by using the synthetic method. In the figure, dashed lines are the synthetic height profiles, $h_{s}$, and solid lines are profiles of residual height plus the estimated synthetic mean, $h^{\prime}+\left\langle h_{s}\right\rangle$. In general, the two profiles agreed closely for all cycles. Away from the Kuroshio Extension, discrepancies are primarily due to the presence of cold- and warm-core rings that were not included in the model. The present model captured the main features of the surface Kuroshio Extension, namely, the position, the cross-track velocity pattern, and the height difference across the stream.

\section{Mean Sea Surface Height Field}

Synthetic height profiles similar to those shown in Figure 2 were estimated for the other 53 subtracks in the Kuroshio Extension region (Figure 1). For each subtrack the mean synthetic height profile was then calculated by averaging the height profiles from all available cycles. Notice that the mean height profile thus calculated is a relative quantity. Although adding any constant offsets to the height profile would not alter the structure of the cross-track velocity component, values of the constant offsets associated with individual subtracks become nontrivial in determining the two-dimensional mean surface height field to which the surface velocity field is related.

One straightforward way to obtain the two-dimensional mean surface height field from the along-track height profiles is to estimate the constant offsets by minimizing the height difference at crossover points (Figure 1). Theoretically, this can be easily done because the number of crossover points in, for example, the latitude band of $30^{\circ}-40^{\circ} \mathrm{N}$ exceeds the 53 unknown offset constants (one constant offset may be chosen arbitrarily to set the reference value for the entire height field). There are two problems related to this simple estimation. First, because the synthetic method focuses on the Kuroshio Extension, the estimated mean height profile along each subtrack is more reliable in the vicinity the Kuroshio Extension than in the far field. Second, and more importantly, the synthetic method assumes that the height jump associated with the Kuroshio Extension remains unchanged away from the stream. The actual mean flow near the Kuroshio Extension includes recirculation gyres [e.g., Masuzawa, 1972; Joyce and Schmitz, 1988], which can modify the sea surface height away from the Kuroshio Extension.

By taking these two factors into consideration, we estimated the two-dimensional mean surface height field by assuming that the mean surface height profile along each subtrack is given by the sum of the synthetic mean height, a constant offset, and possible modifications by large-scale mean circulations on both sides of the Kuroshio Extension:

$$
\begin{aligned}
h_{m}(y)=< & h_{s}(y)>+c-\left[\alpha H\left(y-y_{m}\right)+\right. \\
& \left.\beta H\left(y_{m}-y\right)\right]\left(y-y_{m}\right)\left[1-\exp \frac{-\left(y-y_{m}\right)^{2}}{2 \sigma^{2}}\right]
\end{aligned}
$$

where $c$ is the constant offset, $y_{m}=\left\langle a_{2}\right\rangle$ is the mean axis position of the Kuroshio Extension, $\sigma$ is the standard deviation of $\left\langle a_{2}\right\rangle$, and $H(y)$ is the Heaviside step function. In (4), $\alpha$ and $\beta$ are the slope parameters associated with the large-scale mean circulations on the northern side and southern sides of the Kuroshio Extension, respectively. The factor $1-\exp \left[-\left(y-y_{m}\right)^{2} / 2 \sigma^{2}\right]$ in (4) forces the last term to vanish near the mean Kuroshio Extension axis position.

By requiring the height difference between the ascending and descending subtracks to vanish at all crossover points within the latitude band of $30^{\circ}-40^{\circ} \mathrm{N}$, we obtained a set of 223 linear equations with 153 unknowns. These equations can be simply expressed by

$$
\mathbf{A x}=\mathbf{y}
$$

where $\mathbf{A}$ is the matrix of the model parameters, $\mathbf{x}$ is a column vector of unknowns, and $y$ is a column vector containing the height difference information. As we noted above, one of the constant offsets can be chosen arbitrarily as a reference for the mean height field. In this study, the offset was chosen to be $2.0 \mathrm{~m}$ at the southwestern corner of the domain so as to give a clearer comparison with the climatological surface height data. The problem posed by (5) is similar to the geostrophic inverse problem studied by Wunsch [1978], Wunsch et al. [1983], and Joyce et al. [1986]. For the overdetermined system of (5), the solution is a conventional least squares solution if the rank of the system equals the number of the unknowns, whereas it becomes an inverse problem if there is a rank deficiency. To solve (5), we first row-weighted each equation by

$$
\exp \frac{1}{2}\left[-\left(\frac{y-y_{m a}}{5 \sigma_{a}}\right)^{2}-\left(\frac{y-y_{m d}}{5 \sigma_{d}}\right)^{2}\right]
$$

so that equations at crossover points near the axis of the Kuroshio Extension are given more weight in determining the unknowns, where $y_{m}$ and $\sigma$ are the same as in (4), and subscripts $a$ and $d$ denote values from ascending and descending subtracks, respectively. Notice that the row weighting accounted for possible larger errors in the height difference values farther away from the Kuroshio Extension. Column weighting, with the weight given by the square root of the column's length, was also applied to (5) in order to obtain maximum numerical stability. The weighted equations of (5) were solved by using the singular value decomposition [Wunsch, 1978]. A detailed discussion of determining the rank of the system is included in the appendix. After the unknowns were determined, the alongtrack height values were converted to a regular grid using a two-dimensional objective method (with the same weighting functions used in section 5 ).

Figure $3 a$ shows the result of the mean surface height field determined from the singular value decomposition calculation. As was previously noted by Kawai [1972], a prominent feature of the upstream portion of the Kuroshio Extension is the existence of two quasi-stationary meanders. The ridges of these quasi-stationary meanders are located at $144^{\circ} \mathrm{E}$ and $150^{\circ} \mathrm{E}$. These values agree well with the ridge positions found in the surface dynamic height maps by Wyrtki [1975a] and Teague et al. [1990] (see Figure 3b), and in the mean sub-surface temperature map by Mizuno and White [1983]. Downstream of the second stationary meander, the mean Kuroshio Extension widens and exhibits a clear southward deflection. On the basis of the long-term mooring ob- 

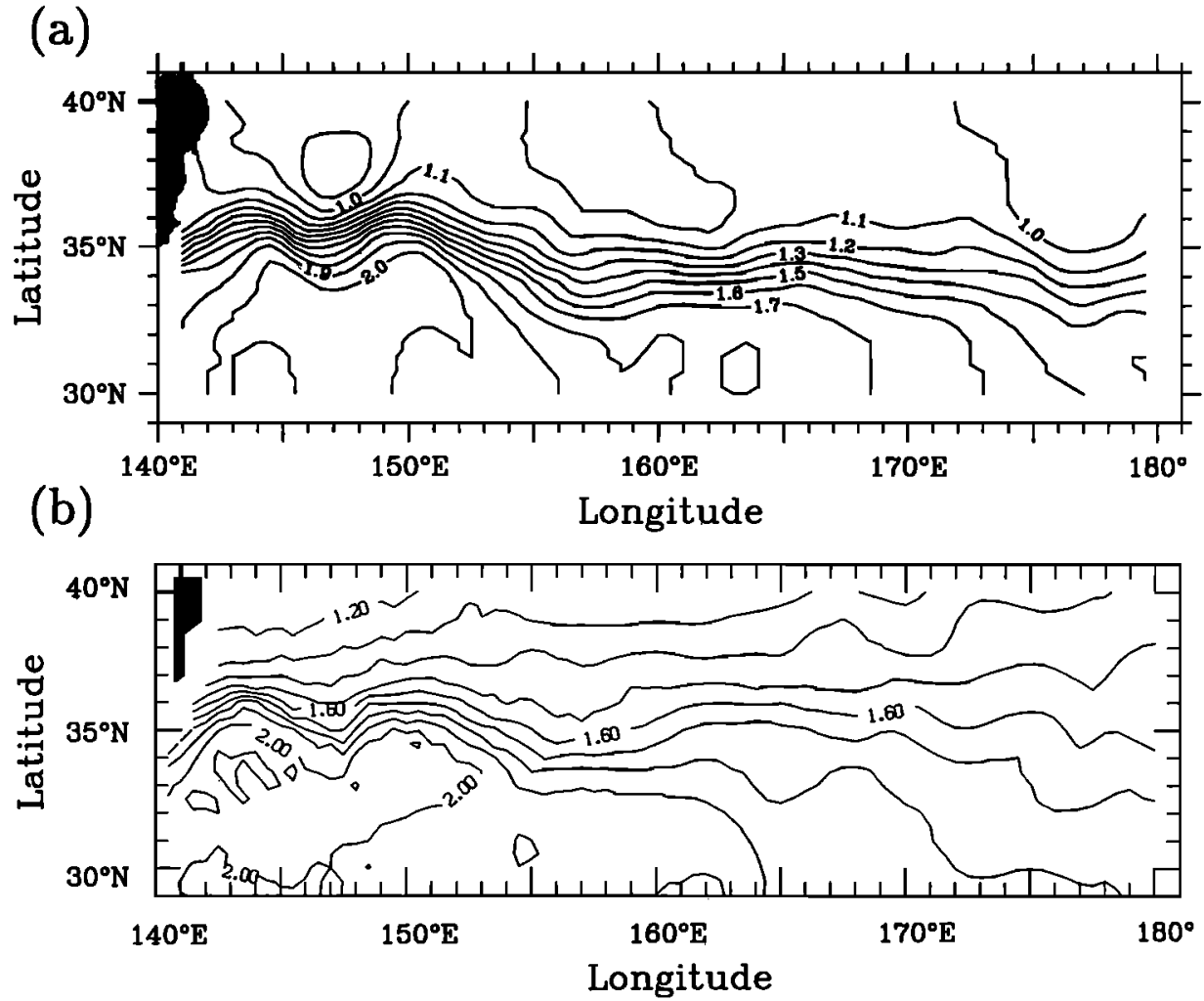

Fig. 3. (a) The mean sea surface height field estimated from the first 2.5 years of Geosat ERM data (November 1987 to April 1989). (b) The climatological mean of the sea surface dynamic height field relative to 1000 dbar [after Teague et al., 1990]. Units are in meters.

servations at $152^{\circ} \mathrm{E}, S c h m i t z$ [1984] and Hall [1989] have noticed the mean velocity of the Kuroshio Extension there directed $35^{\circ}$ to the south of east, a result consistent with the present study. A close comparison between Figure $3 a$ and the climatological mean dynamic height field of Figure $3 b$ shows that the Kuroshio Extension axis (as can be defined between isopleths of $1.2 \mathrm{~m}$ and $1.3 \mathrm{~m}$ for Figure $3 a$ and $1.6 \mathrm{~m}$ and $1.7 \mathrm{~m}$ for Figure $3 b$ ) in the two maps coincides well throughout the region under consideration. The height difference across the Kuroshio Extension, however, is generally larger in Figure $3 a$ than that obtained in Figure $3 b$. One reason for this may be the different cross-stream resolution of the Geosat ERM data and the climatological mean data $\left(1^{\circ}\right.$ average). Averaging over different time periods may be another factor causing the discrepancy. A third possible reason for the discrepancy is that the dynamic height values in Figure $3 b$ were relative to $1000 \mathrm{dbar}$. On the basis of the mooring measurements at $152^{\circ} \mathrm{E}$ and $35^{\circ} \mathrm{N}$, Hall [1989] noted that the Kuroshio Extension had a large, alongstream mean velocity component (about $11 \mathrm{~cm} \mathrm{~s}^{-1}$ at the depth of $1335 \mathrm{~m}$ ). Integrating the velocity values across the Kuroshio Extension (Figure 3 of Hall [1989]), we found that the heght jump, $\delta h=g^{-1} f \int u d y$, was still in the magnitude of $15 \mathrm{~cm}$ at the $1335-\mathrm{m}$ depth $(\delta h=41 \mathrm{~cm}$ at the $625-\mathrm{m}$ depth). Thus choosing the reference level at 1000 dbar very likely underestimates the surface height jump across the Kuroshio Extension. On the southern side of the Kuroshio Extension, both maps indicate a southward divergence of height contours, a signal suggesting possible large-scale recirculation gyres. The main discrepancies between the two results appear on the northern side of the Kuroshio Extension. The gradual height decrease northward in Figure $3 b$ is possibly associ- ated with the subarctic gyre of the North Pacific, which is not modeled in our present analysis.

Figure 4 shows the mean surface height difference across the Kuroshio Extension (solid line) and its standard deviation (dashed lines). The mean surface height difference is about $0.75 \mathrm{~m}$ immediately after the Kuroshio Extension leaves the coast of Japan. It reaches the maximum range of $1.2 \mathrm{~m}$ in the region between the two stationary meanders. After $152^{\circ} \mathrm{E}$, the mean height difference stays at a

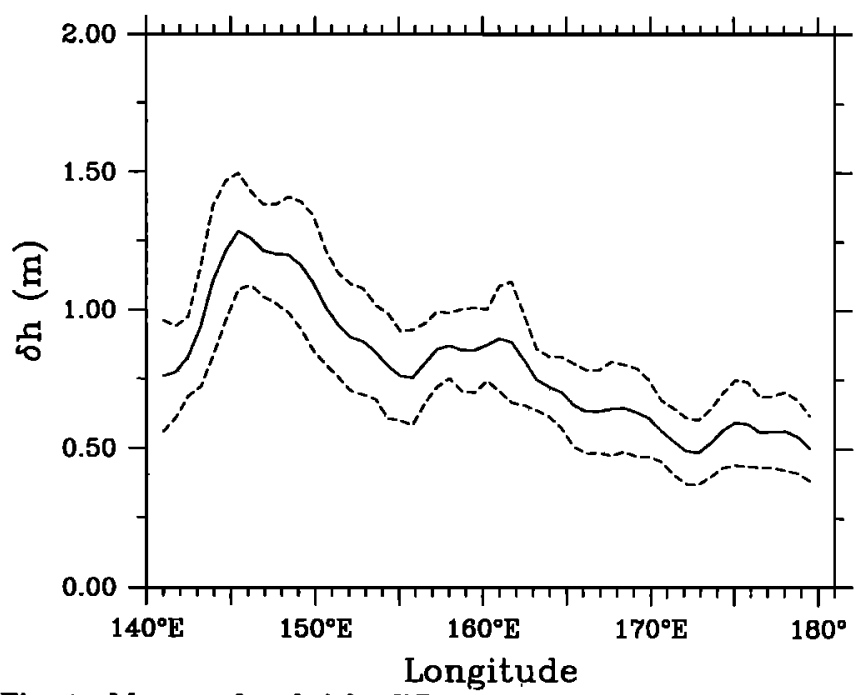

Fig. 4. Mean surface height difference across the Kuroshio Extension (solid line) from the first 2.5 years of Geosat ERM data. Intervals of 1 standard deviation are indicated in the figure by dashed lines. 
nearly constant value, $0.85 \mathrm{~m}$, until the Kuroshio Extension reaches the Shatsky Rise around $159^{\circ} \mathrm{E}$. East of the Shatsky Rise, there is a large decrease in the height difference. Another noticeable drop in the height difference occurs around $171^{\circ} \mathrm{E}$, where the Emperor Seamounts are located. Since the decrease in the height difference east of $150^{\circ} \mathrm{E}$ coincides with the southward deflection of the height contours (Figure $3 a)$, we speculate that the decrease in the height difference is related to the confinement of the recirculation gyre by large-scale topographic features.

\section{Deriving Instantaneous Surface Height Fields AND COMPARISON WITH AVHRR IMAGES}

In the previous sections, we estimated the mean sea surface height field in the Kuroshio Extension region by extending the synthetic method of Kelly and Gille [1990]. The mean sea surface height field thus estimated compared well with the mean dynamic height field derived from the conventional dynamic methods. With this mean height field in hand, it is now possible to obtain a time series of instantaneous surface height fields by adding the mean sea surface height to the time-dependent residual height data. In this section we will first briefly discuss the derivation of the residual height fields. The resultant instantaneous surface height fields are then compared with the available advanced very high resolution radiometer (AVHRR) images for the period in spring 1987. This comparison is useful not only in validating our synthetic method but also in comfirming the accuracy of the instantaneous surface height data, upon which our subsequent analyses of the Kuroshio Extension will depend.

Since the residual height data of the Geosat ERM are irregularly sampled in time and space along ascending and descending subtracks and are sometimes missing entirely, it is necessary to regrid and smooth the data onto a regular timespace grid. This is done in the present study using the threedimensional objective analysis method [Levitus, 1982]. In essence, the objective analysis method estimates the residual height value on each grid point by averaging the neighboring observational data with a distance-weighting function proportional to

$$
\exp \left[-\left(\frac{2 \Delta x}{R_{x}}\right)^{2}-\left(\frac{2 \Delta y}{R_{y}}\right)^{2}-\left(\frac{2 \Delta t}{R_{t}}\right)^{2}\right]
$$

where $\Delta x, \Delta y$, and $\Delta t$ are distances from the grid point to the observation point in the $x, y$, and $t$ directions and $R_{x}, R_{y}$, and $R_{t}$ are the influence radii in these respective directions.

In order to choose consistent values for the spatial and temporal influence radii, we calculated the space-time crosscorrelation functions between the residual height profiles averaged over the whole Kuroshio Extension region (Figure $5 a$ ). Since the cross-track spatial and temporal resolutions of the Geosat ERM data are about $150 \mathrm{~km}$ and 17 days, respectively, for the Kuroshio Extension region, Figure 5 a suggests that the height data from the same track at the previous and subsequent cycles are more important than those from the same cycle at adjacent tracks in interpolating the residual height fields. In Figure $5 a$ the decorrelation scales in $x$ and $t$ (the first zero crossings) are $225 \mathrm{~km}$ and 90 days, respectively. These values are close to those found by Bernstein and White [1981], who estimated the temporal

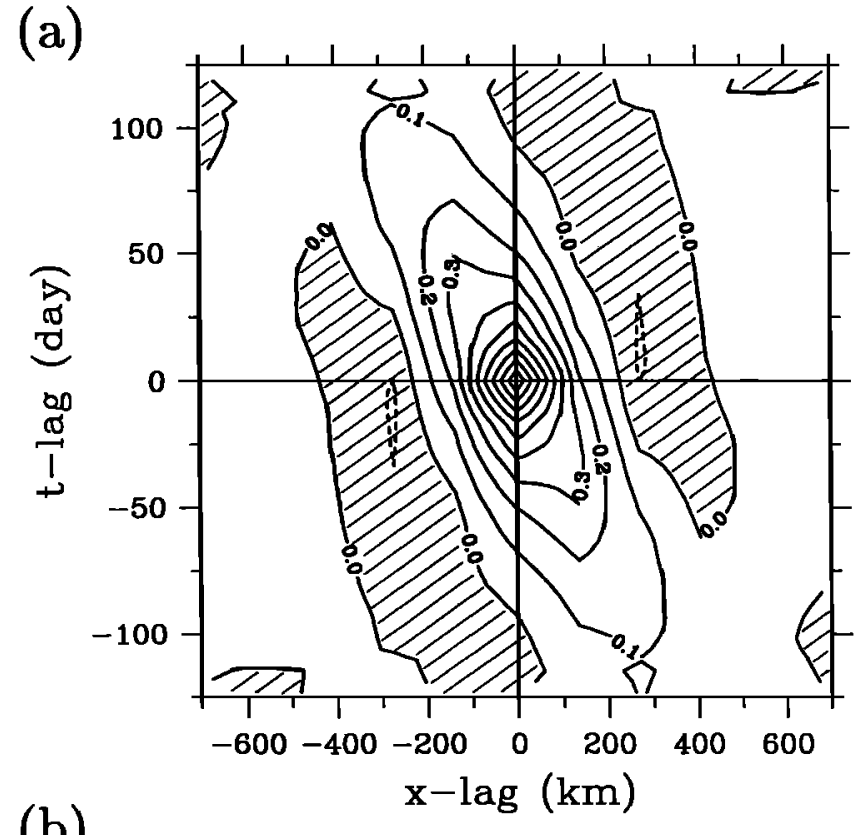

(b)

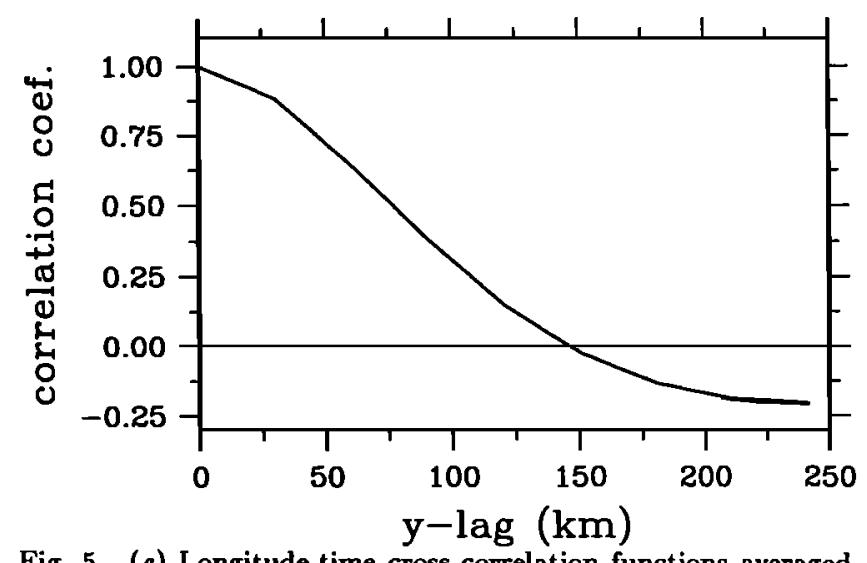

Fig. 5. (a) Longitude-time cross-correlation functions averaged over the Kuroshio Extension region $\left(30^{\circ}-40^{\circ} \mathrm{N}, 141^{\circ}-180^{\circ} \mathrm{E}\right)$. The calculation is based on the residual height data along descending subtracks of the Geosat ERM. (b) The autocorrelation functions in the alongtrack direction. A veraged over the same region as in Figure $5 a$.

and longitudinal decorrelation scales in the Kuroshio Extension region to be 2 months and 2 degrees based on the $300-\mathrm{m}$ water temperature data. To determine the influence radius in the $y$-direction, we calculated in Figure $5 b$ the averaged spatial autocorrelation functions along residual height profiles. The decorrelation scale in the alongtrack direction is about $140 \mathrm{~km}$, a typical width scale in the Kuroshio Extension [Hall, 1989]. Based on the results of Figure 5, the influence radii for the objective analysis were chosen to be the scales in which the corresponding autocorrelation functions decrease to 0.2 , namely, $R_{x}=150 \mathrm{~km}, R_{y}=110 \mathrm{~km}$, and $R_{t}=50$ days. (Strictly speaking, $R_{y}=110 \mathrm{~km}$ is the scale averaged along ascending and descending tracks, which are not due north. Because the departure of the tracks from the north is small, we regarded this value to be in the $y$ direction)

Figure 6 shows the estimated (absolute) surface height fields from February 8 to May 5, 1987. This particular period is chosen because of the availability of relatively cloudfree AVHRR images. In Plate 1 , four AVHRR images taken 
(a) Feb 9, 1987

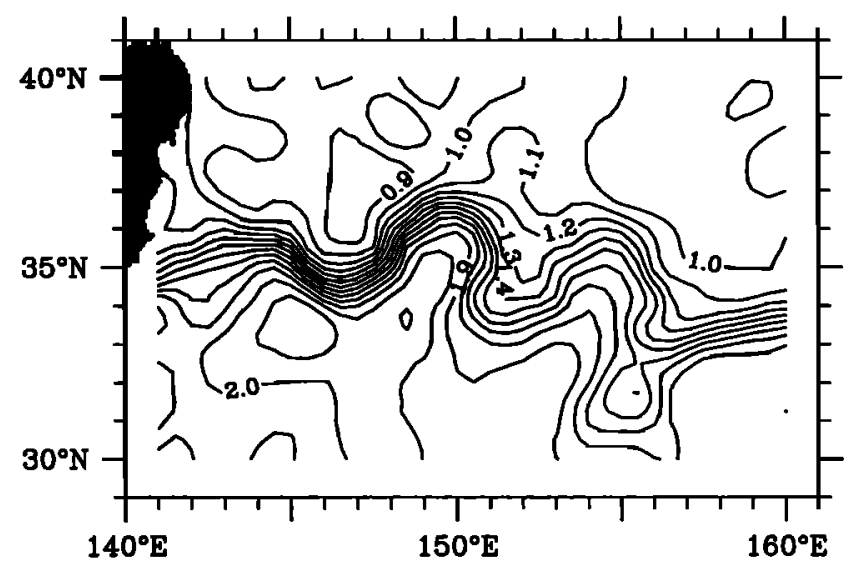

(b) Feb 26, 1987

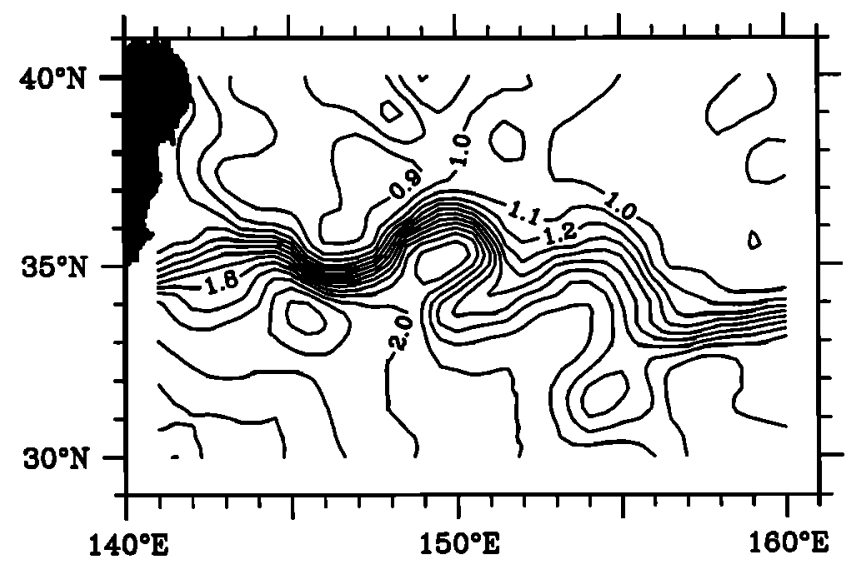

(c) $\operatorname{Mar} 15,1987$

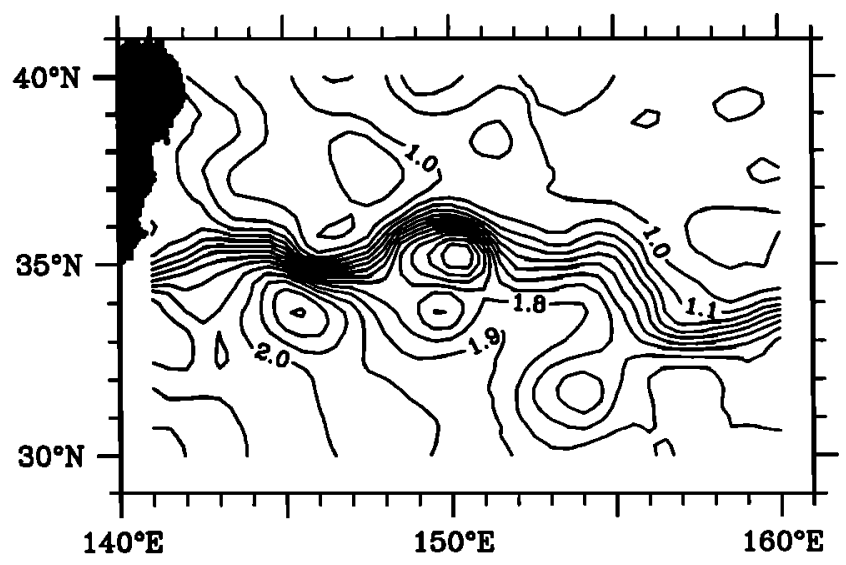

(d) Apr 1, 1987

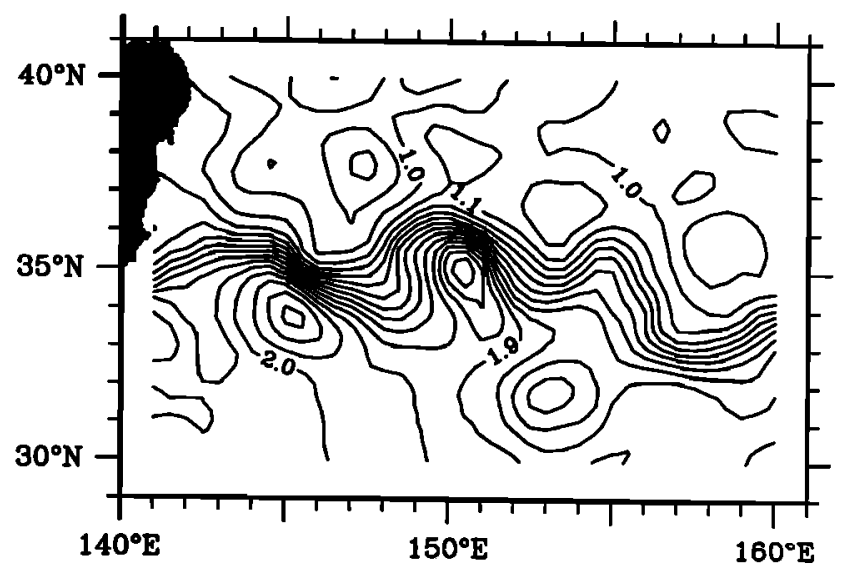

(e) Apr 18, 1987

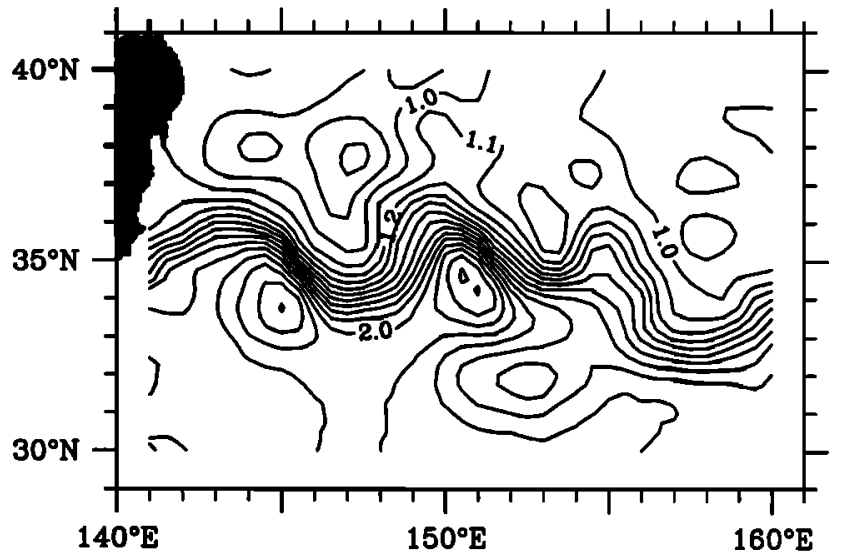

(f) May 5, 1987

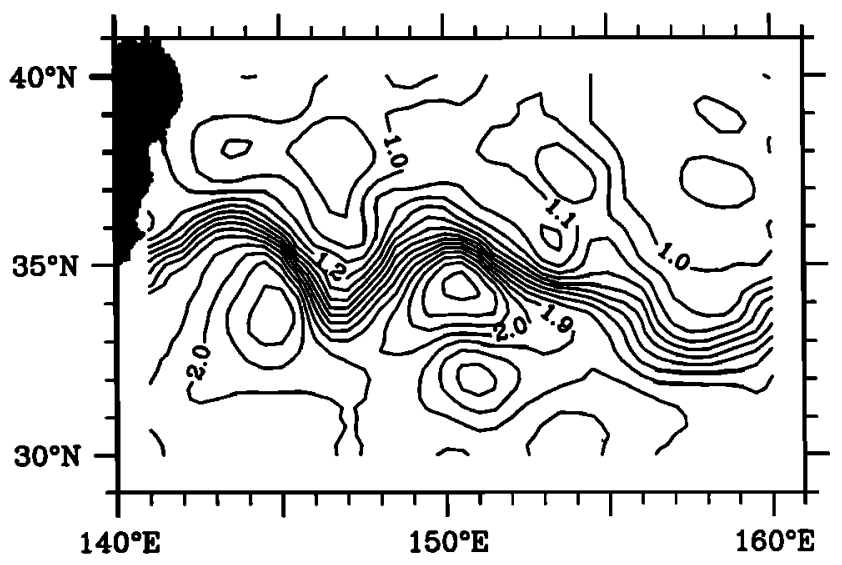

Fig. 6. The surface height fields for (a) February 9, (b) Febuary 26, (c) March 15, (d) April 1, (e) April 18, and $(f)$ May 5, 1987. These fields are obtained by adding the residual height data to the synthetic mean height field shown in Figure 3a. Units are in meters.

by the NOAA 9 satellite on February 10, April 5, April 18, and May 8 are overlain with the surface height field. In the image, the warm Kuroshio Extension water is indicated by red/orange colors. Within this 3 -month period, the path of the Kuroshio Extension changed greatly downstream of $145^{\circ} \mathrm{E}$ near the second quasi-stationary meander. At the beginning of February, both the sea surface height pattern (Figure 6a) and the AVHRR image (Plate 1a) showed that the second meander was oriented northeast-southwestward and was followed immediately by a sharp southward detour of the Kuroshio Extension. From the middle of February through March, the southward detour of the Kuroshio Extension developed further and eventually pinched off from the main stream to form a weak cold-core ring (Figures $6 b$ and $6 c$ ). Unfortunately, no clear AVHRR images are available during these two cycles.

By the beginning of April, the second meander $\left(150^{\circ} \mathrm{E}\right)$ exhibited a somewhat different appearance with its orienta- 
(a) Feb 10, 1987

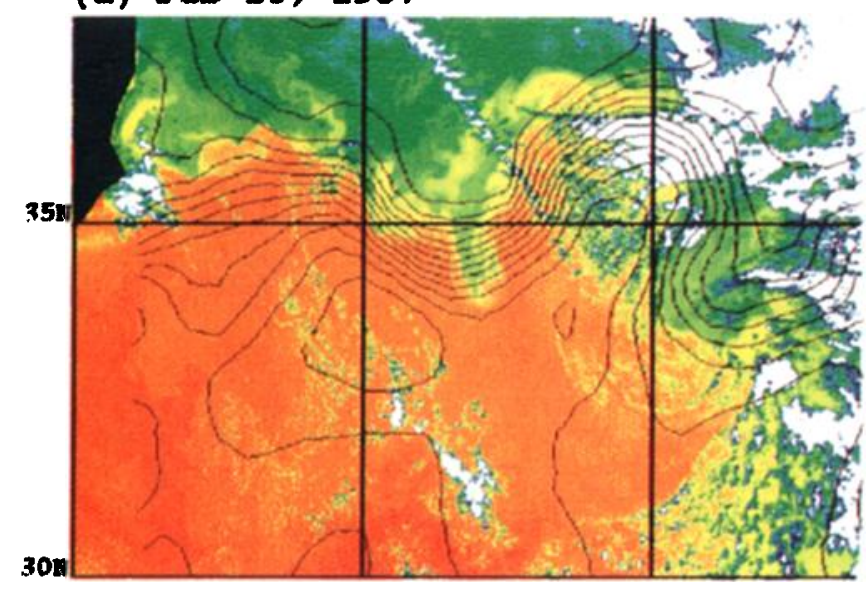

(b) Apr 5, 1987

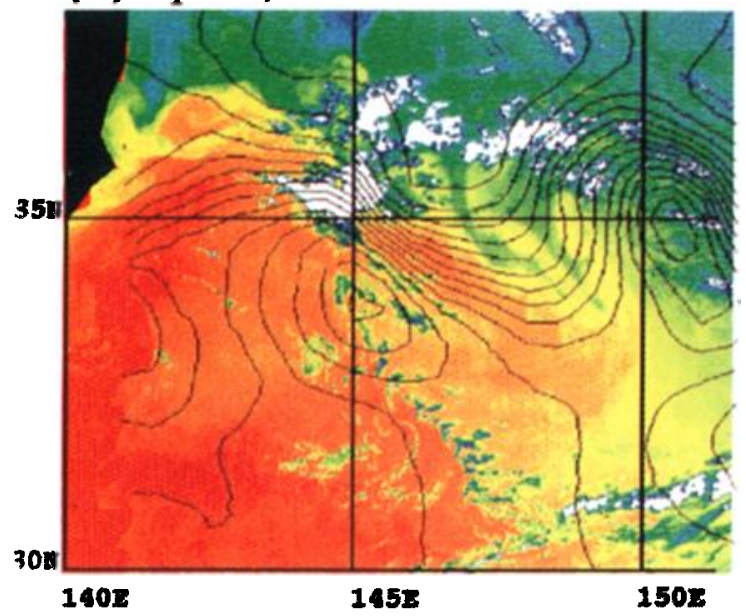

(c) Apr 18, 1987

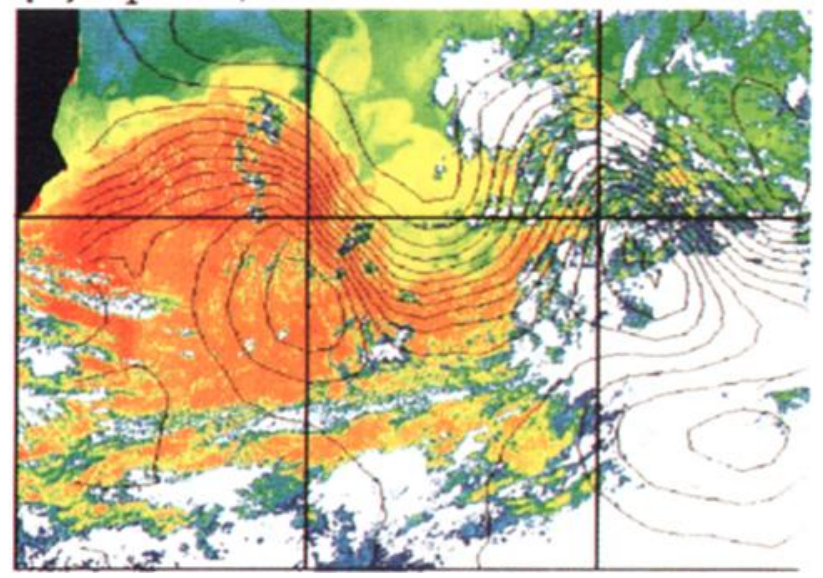

(d) May 8, 1987

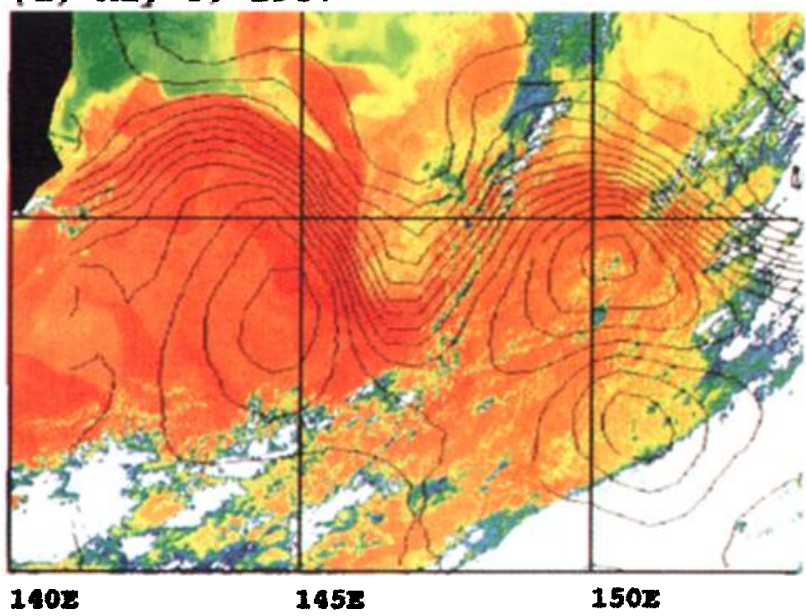

Plate 1. NOAA 9 satellite infrared images for (a) Febuary 10, (b) April 5, (c) April 18, and (d) May 8, 1987. Superimposed on the images by solid lines are the surface height contours derived from the Geosat ERM (compare Figure 6).

tion directed northwest-southeastward (Figure 6d). Moreover, there was a steep southward detour of the Kuroshio Extension on the upstream side of the second meander. A similar picture is shown in Plate $1 b$, where a cold tongue can be seen to extend sharply southeastward from $145^{\circ} \mathrm{E}$ to $149^{\circ} \mathrm{E}$. On the subsequent cycles around April 18 and May 5 , both the sea surface height data (Figures $6 e$ and $6 f$ ) and the AVHRR images (Plate $1 c$ and $1 d$ ) revealed that the northern boundary of the first meander shifted north by a degree as compared to its former latitude. Comparing Figure $6 e$ with $6 f$ shows that the trough (near $147^{\circ} \mathrm{E}$ ) between the two quasi-stationary meanders narrowed considerably during the 17 days. Again, this is the situation observed in the AVHRR data. Around May 5, no tilt of the second meander was seen in either Figure $6 f$ or Plate $1 d$.

Discrepancies also exist between the sea surface height patterns obtained in the present study and the AVHRR data. For example, the warm streamers which appear in the AVHRR data at $142.5^{\circ} \mathrm{E}, 36.5^{\circ} \mathrm{N}$, on April 5 and at $145.5^{\circ} \mathrm{E}$, $37^{\circ} \mathrm{N}$, on May 8 were not seen in the sea surface height fields. Also, the southward detours of the Kuroshio Extension in the sea surface height fields are in general not as sharp as those that appearing in the AVHRR data. We believe that these discrepancies are due primarily to the limitation in the resolution of the Geosat ERM data and due to the fact that the altimetry measurement is not synchronized spatially (at least 3 days lag between the adjacent tracks). Despite the energetic fluctuations of the Kuroshio Extension within this short period, our estimated instantaneous sea surface height fields faithfully captured the major changes occurring in the Kuroshio Extension. In the next section, we will use this time series of the surface height fields to explore the temporal and spatial variability in the Kuroshio Extension region.

\section{VARIABILITY IN THE KUROShIo EXTEnsion Region}

\subsection{Mean and Eddy Kinetic Energy Distributions}

The eddy and mean kinetic energy (abbreviated hereinafter as EKE and MKE) distributions in the Kuroshio Extension region were computed using the objectively mapped surface height data calculated in the previous sections. The maximum value of the $\operatorname{EKE}\left(0.45 \mathrm{~m}^{2} \mathrm{~s}^{-2}\right)$ appears in the region around $146^{\circ} \mathrm{E}$ and $34^{\circ}-36^{\circ} \mathrm{N}$ (Plate $2 a$ ) between the two quasi-stationary meanders. Vigorous changes in the orientation of the second meander (Figure 6 and Plate 1) and the formation of cold-core eddies are possible causes for this maximum. The EKE values around $144^{\circ} \mathrm{E}$ and $36^{\circ} \mathrm{N}$ are smaller than those around $149^{\circ} \mathrm{E}$ and $36^{\circ} \mathrm{N}\left(0.29 \mathrm{~m}^{2} \mathrm{~s}^{-2}\right.$ versus $0.35 \mathrm{~m}^{2} \mathrm{~s}^{-2}$ ), suggesting that the first quasi-stationary meander is more stable in time than its downstream coun- 
terpart. The MKE value in this portion of the Kuroshio Extension remains comparatively constant along the stream axis $\left(0.28 \mathrm{~m}^{2} \mathrm{~s}^{-2}\right)$. On the basis of the current meter data at a $350-\mathrm{m}$ depth at $152^{\circ} \mathrm{E}$ and $35^{\circ} \mathrm{N}$, Hall [1989] estimated the EKE and MKE values there to be $0.1153 \mathrm{~m}^{2} \mathrm{~s}^{-2}$ and $0.0958 \mathrm{~m}^{2} \mathrm{~s}^{-2}$, respectively (EKE/MKE $=1.2$ ). At the surface, these values at $152^{\circ} \mathrm{E}$ are $0.237 \mathrm{~m}^{2} \mathrm{~s}^{-2}$ and $0.128 \mathrm{~m}^{2} \mathrm{~s}^{-2}$ with a ratio of 1.8 in the present study.

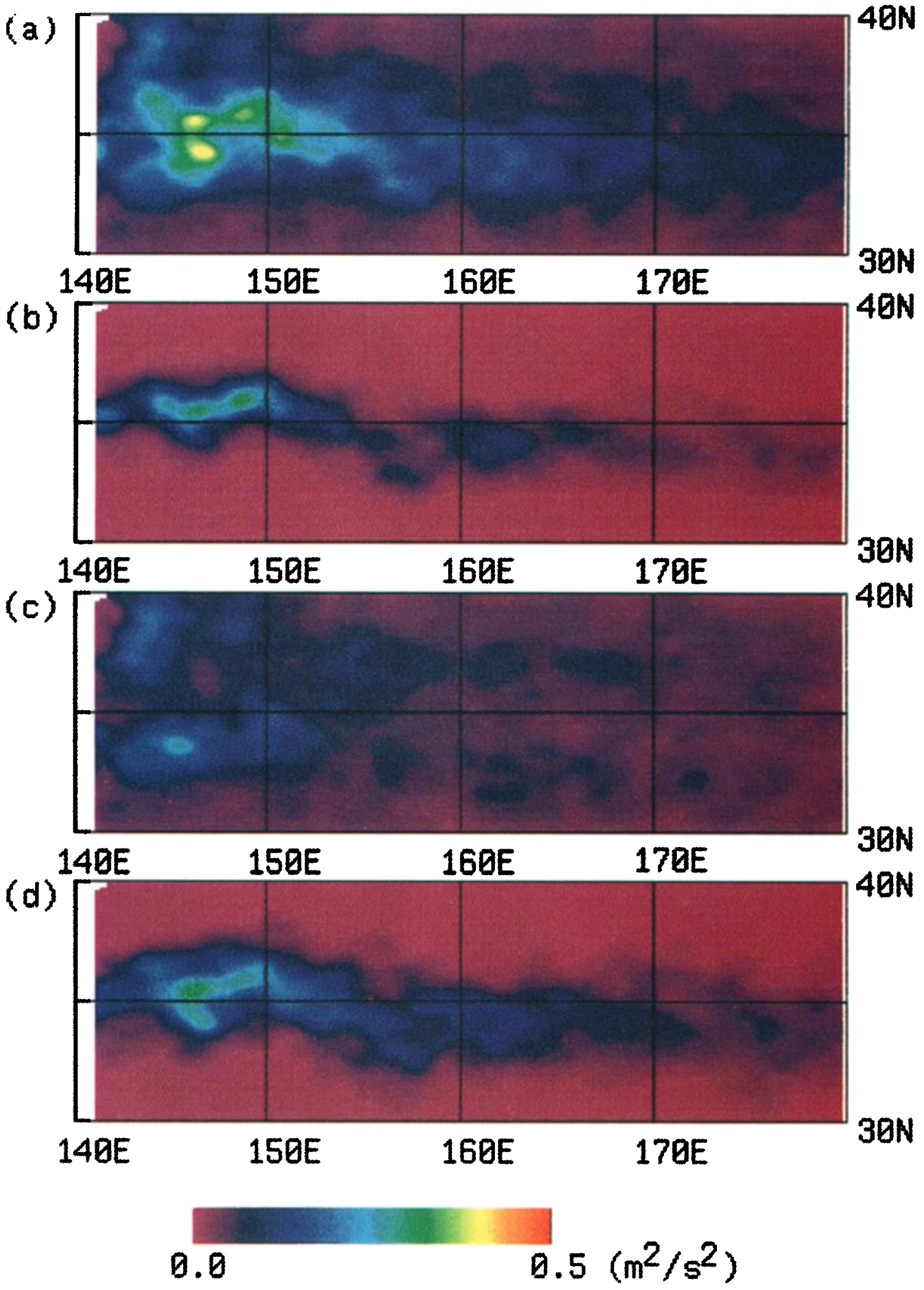

Plate 2. Kinetic energy distributions in the Kuroshio Extension region: (a) the eddy kinetic energy (EKE), (b) the mean kinetic energy (MKE), (c) the EKE associated with the fluctuations outside the Kuroshio Extension, and $(d)$ the EKE associated with the fluctuations of the Kuroshio Extension (see text for definitions). 
Downstream of $152^{\circ} \mathrm{E}$, both EKE and MKE values drop significantly owing to broadening of the Kuroshio Extension. Secondary energy peaks in the EKE and MKE distributions reappear east of the Shatsky Rise near $160^{\circ} \mathrm{E}$, and the energy values thereafter decrease steadily. These features of the MKE are also clearly seen in Figure 7 , in which we averaged the MKE values between $33^{\circ} \mathrm{N}$ and $37^{\circ} \mathrm{N}$ and plotted them as a function of longitude (solid line).

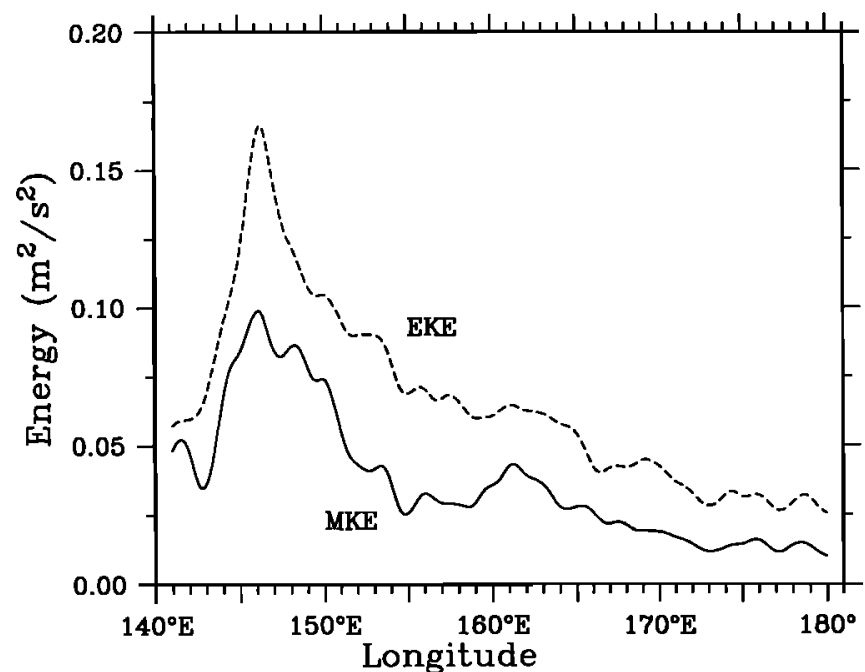

Fig. 7. Mean kinetic energy and eddy kinetic energy of the Kuroshio Extension averaged between $33^{\circ} \mathrm{N}$ and $37^{\circ} \mathrm{N}$. The values of MKE and EKE are based on averages of the results in Plate $2 b$ and Plate $2 d$, respectively.

The synthetic method used in the present study further allows us to divide the residual velocity into two components: one associated with the fluctuations of the Kuroshio Extension itself (determined by the residual height data of $h_{s}-<h_{s}>$ ) and the other associated with the fluctuations outside the Kuroshio Extension, such as rings and waves (determined by the residual height data of $h^{\prime}+\left\langle h_{s}\right\rangle-h_{s}$ ). In Plate $2 c$ and $2 d$, we calculated the EKE distributions based on the velocity components associated with warm-core and cold-core rings and those associated with the Kuroshio Extension, respectively. The activity of the warm-core rings is most intensive north of the two quasi-stationary meanders. Compared with the warm-core rings, cold-core ring activity occurs relatively close to the axis of the Kuroshio Extension. This result supports previous observations that in the Kuroshio Extension region most cold-core rings appear and move near the vicinity of the current axis, whereas northward excursions by warm-core rings may reach as far as $42^{\circ} \mathrm{N}$ [Mizuno and White, 1983]. The presence of the coast, which exerts an image effect on warm-core rings, has been shown by Yasuda et al. [1986] to possibly cause such a difference.

A close look at the EKE distribution in Plate 2a indicates that there are two peaks in the maximum energy value region between the two quasi-stationary meanders near $145^{\circ} \mathrm{E}$. Separation of the EKE fields in Plate $2 c$ and $2 d$ revealed that the northern peak at $35.5^{\circ} \mathrm{N}$ is induced by the Kuroshio Extension fluctuations, whereas the southern peak at $34^{\circ} \mathrm{N}$ is related to the presence of cold-core rings. For comparison with the meridional mean of MKE shown in Figure 7, we calculated the meridional mean of the EKE associated with the Kuroshio Extension (shown by the dashed line in Figure 7). It is worth noticing that the ratio of $\mathrm{EKE} / \mathrm{MKE}$ remains about the same, a factor of $1.5-2.0$, downstream of $151^{\circ} \mathrm{E}$.

The energy distributions calculated from the Geosat data in Plate 2, especially that of the MKE, are similar in pattern to those obtained by Nishida and White [1982] using the dynamic height (100/1000 dbar) data. For example, Nishida and White also found that the MKE is maximum in the two quasi-stationary meander region, and it drops abruptly after $155^{\circ} \mathrm{E}$ and attains a secondary maximum near the Shatsky Rise. The energy values in their study, however, are about an order of magnitude smaller than those in Plate 2. This underestimation of the energy values is essentially due to the coarse resolution ( $1^{\circ}$ by $1^{\circ}$ average) of the height data available then for their study.

\subsection{Propagation of Mesoscale Fluctuations}

As can be seen from the space-time cross-correlation function in Figure 5a, fluctuations in the surface height fields of the Kuroshio Extension region tend to propagate westward (the average speed is $2.8 \mathrm{~cm} \mathrm{~s}^{-1}$ ). Two questions immediately arising are whether aspects of this propagation differ inside and outside of the Kuroshio Extension, and whether there is any zonal dependence induced, for example, by the abrupt topographic change of the Shatsky Rise. Notice that using these separate residual height components in the calculation enables us to investigate the propagation characteristics in the Kuroshio Extension and those in the neighboring fields individually.

In the following analysis, we separated the study domain into three zonal bands: the Kuroshio Extension (33 ${ }^{\circ}-$ $37^{\circ} \mathrm{N}$ ), the region north of the Kuroshio Extension $\left(36^{\circ}-\right.$ $\left.40^{\circ} \mathrm{N}\right)$, and the region to the south $\left(30^{\circ}-34^{\circ} \mathrm{N}\right)$. Each of these zonal bands was further divided into upstream and downstream subregions with a division at $157^{\circ} \mathrm{E}$ just upstream of the Shatsky Rise. Space-time cross-correlation functions were calculated using the residual height component $\left(h_{s}-<h_{s}>\right)$ for the Kuroshio Extension subregions and the component $\left(h^{\prime}+<h_{s}>-h_{s}\right)$ for the other four subregions. Although the northern and southern zonal bands overlap the zonal band of the Kuroshio Extension by $1^{\circ}$ latitude, the cross-correlation functions calculated in Figure 8 are independent because they are based on separate residual height components.

On the southern side of the Kuroshio Extension, we found no significant difference in the cross-correlation functions between the upstream and downstream subregions (Figure $8 c$ ). The westward propagation is obvious and has a speed of 5.7 $\mathrm{cm} \mathrm{s}^{-1}$. In the upstream portion of the Kuroshio Extension (Figure $8 b$, left panel), the fluctuations are stationary (though one can discern weak eastward propagation based on boundaries of shaded negative correlation regions). In the downstream Kuroshio Extension subregion the westward propagation prevails again, and the propagation speed there is $2.6 \mathrm{~cm} \mathrm{~s}^{-1}$. In the upstream region north of the Kuroshio Extension (Figure 8a), the decorrelation scales in time and space are the smallest in our study region. This is caused by extensive latitudinal movement of warm eddies offshore of the east coast of Japan [e.g., Yasuda et al., 1991]. In the downstream region of the northern band, the propagation is again clearly westward. The average speed of propagation is $2.5 \mathrm{~cm} \mathrm{~s}^{-1}$, not significantly different from the value observed in the downstream region of the Kuroshio Extension $\left(2.6 \mathrm{~cm} \mathrm{~s}^{-1}\right)$.

The fact that the westward propagation of mesoscale fluctuations decreases with latitude in the Kuroshio Extension 
(a)

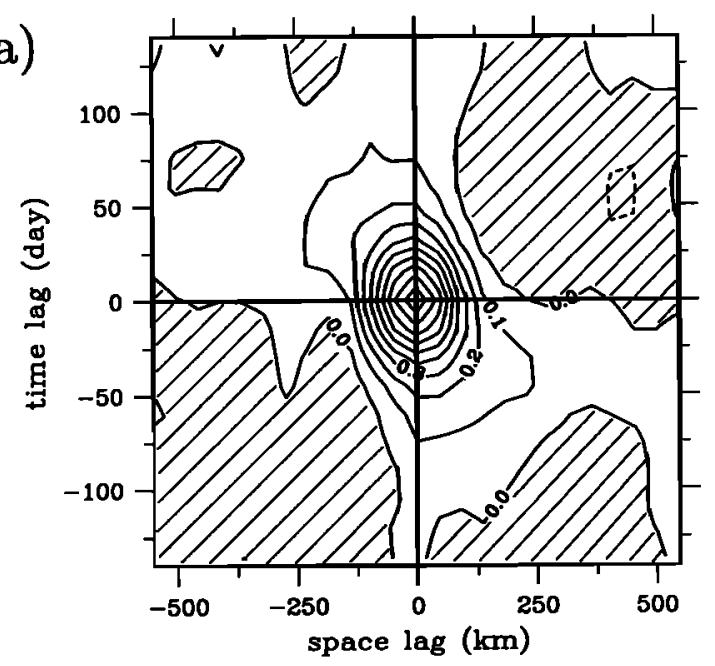

(b)

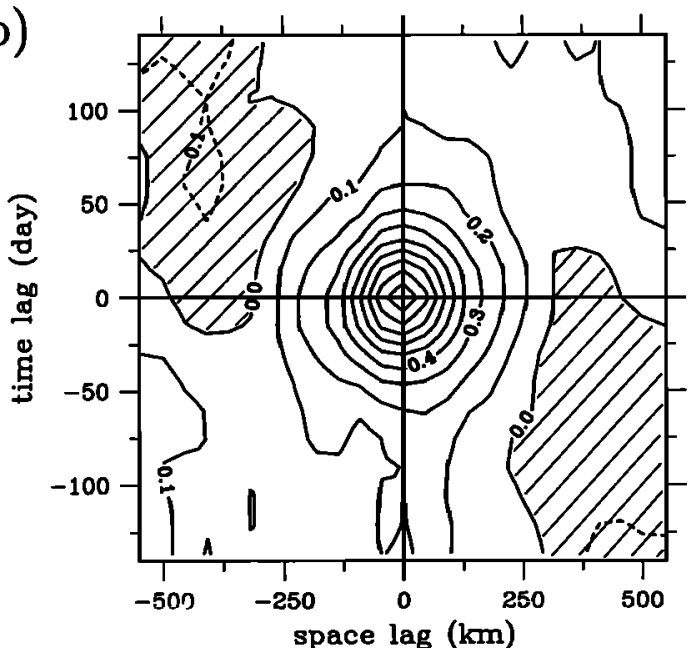

(c)

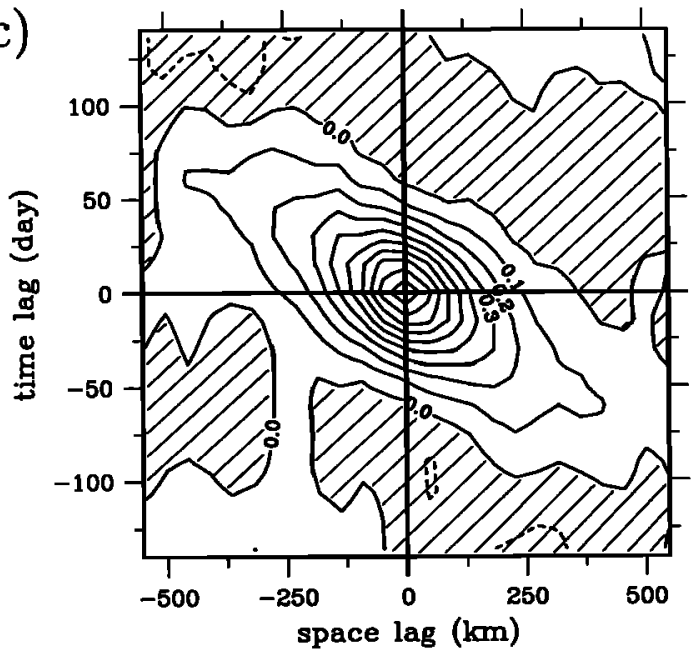

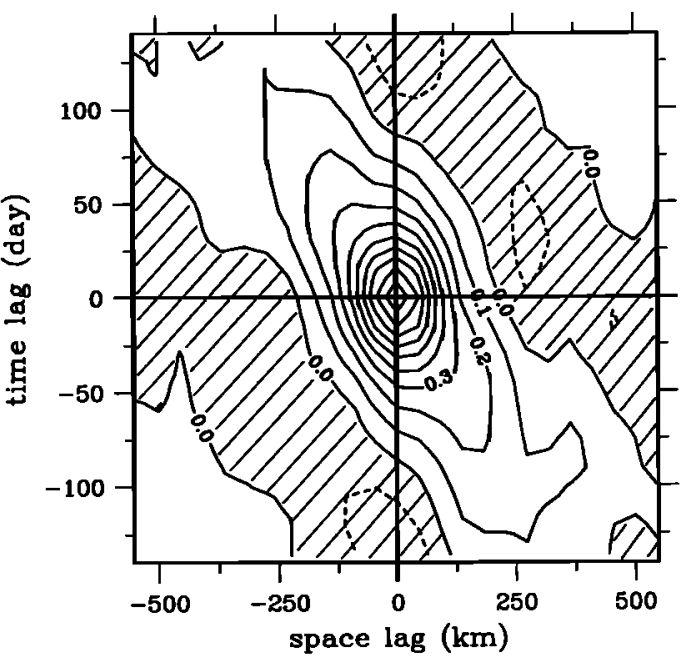
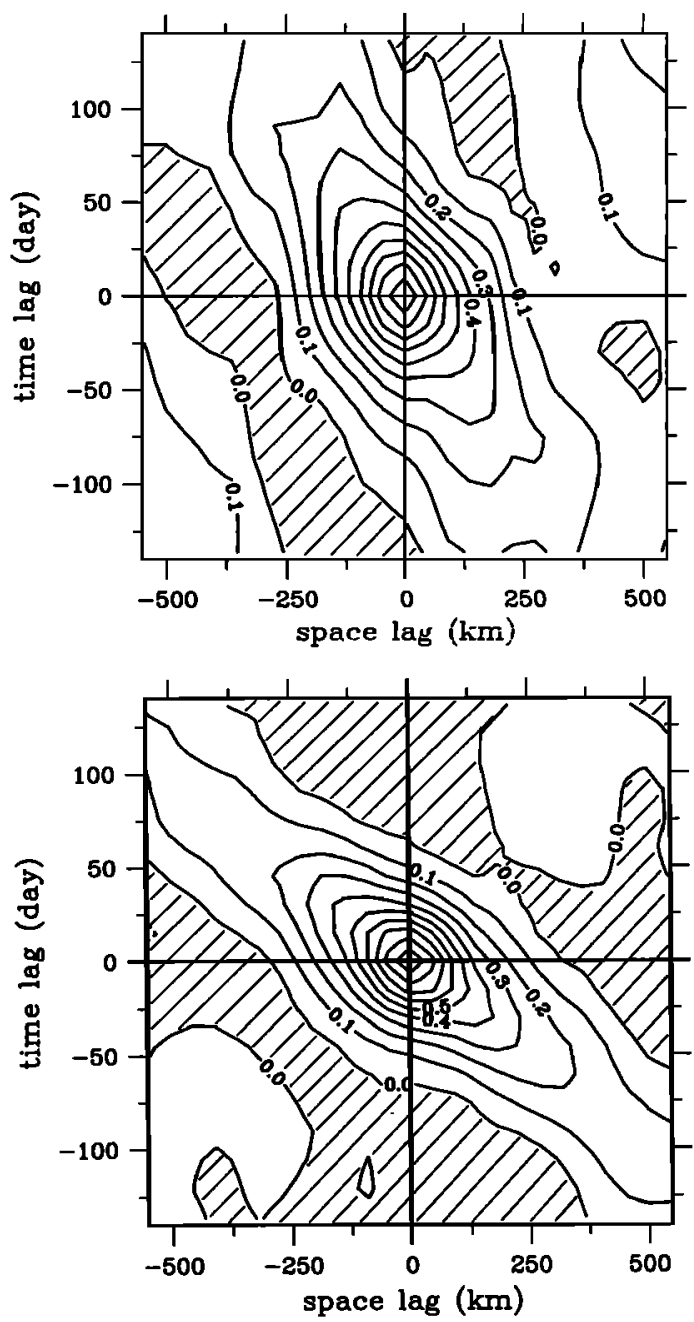

Fig. 8. Longitude-time cross-correlation functions in the (left) upstream and (right) downstream regions of three zonal bands: $(a)$ the northern band $\left(36^{\circ}-40^{\circ} \mathrm{N}\right),(b)$ the Kuroshio Extension band $\left(33^{\circ}-37^{\circ} \mathrm{N}\right)$, and $(c)$ the southern band $\left(30^{\circ}-34^{\circ} \mathrm{N}\right)$. The results in Figures $8 a$ and $8 c$ are based on the residual height data of $h^{\prime}+\left\langle h_{s}\right\rangle-h_{s}$, and results in Figure $8 b$ are based on data of $h_{s}-\left\langle h_{s}>\right.$. Shaded regions indicate negative correlation.

region was previously noticed by Bernstein and White [1981] in their analysis of XBT data. They attributed the difference in the phase propagation to the decrease in the baroclinic long-wave speed with latitude. Also based on water temperature data, Mizuno and White [1983] observed an eastward propagation (with a speed of $0.4-1.4 \mathrm{~cm} \mathrm{~s}^{-1}$ ) in the region of $32^{\circ}-42^{\circ} \mathrm{N}$ and $130^{\circ}-154^{\circ} \mathrm{E}$. No particular reason, however, was given for this eastward propagation (note that Mizuno and White's result included the Kuroshio region south of Japan). By analyzing the first year of Geosat data, Tai and White [1990] have also detected westward propagations on the northern and southern sides of the Kuroshio Extension. 
The westward propagation speed averaged between $150^{\circ} \mathrm{E}$ and $170^{\circ} \mathrm{E}$ was $1.9 \mathrm{~cm} \mathrm{~s}^{-1}$ along $40^{\circ} \mathrm{N}$ and $6.5 \mathrm{~cm} \mathrm{~s}^{-1}$ along $30^{\circ} \mathrm{N}$. Both of these values are similar to those found in Figures $8 a$ and $8 c$, which are based on the 2.5-year time series. Along $35^{\circ} \mathrm{N}$ between $150^{\circ} \mathrm{E}$ and $170^{\circ} \mathrm{E}$, Tai and White [1990] found no significant propagations, a result different from Figure $8 b$ in the downstream region. One possible reason for this difference is that their analysis was geographically fixed, whereas the present study fixed the coordinates on the path of the Kuroshio Extension (recall Figure $8 b$ was based on the residual height data of $h_{s}-<h_{s}>$ ).

Since the propagation speeds found in Figure 8 are not a simple decreasing function with latitude as would be predicted by the simple linear wave dynamics, we consider below the roles played by mean flows in the propagation speed determination. Apart from the apparent possible influence exerted by the mean Kuroshio Extension, this analysis was further motivated by recent observations by Schmitz [1988] and Joyce and Schmitz [1988], whose long-term mooring results revealed the existence of significant mean flows in the deep layer of the Kuroshio Extension region.

Suppose the ocean is composed of two layers with mean flows of $U_{1}$ and $U_{2}$ in each of the layers. It can be easily shown that the dispersion relation for long baroclinic Rossby waves satisfies

$$
c=U_{2}-\frac{\beta}{R_{1}^{-2}+R_{2}^{-2}}+\frac{U_{1}-U_{2}}{1+H_{2} / H_{1}}
$$

[cf. Pedlosky, 1979], where $R_{n}=\left(g^{\prime} H_{n}\right)^{1 / 2} f^{-1}$ is the internal Rossby radius for the $n$-th layer, $H_{n}$ is the layer's thickness, and $\beta$ is the meridional derivative of the Coriolis parameter $f$. Ignoring the advective effects in (7) leads to the result of $c$, the phase speed (negative westward), being proportional to $f^{-2}$. Taking the mean values of $H_{1}=800$ $\mathrm{m}, H_{2}=4000 \mathrm{~m}$, and $g^{\prime}=1.5 \mathrm{~cm}^{2} \mathrm{~s}^{-1}$ (from Figures $14 p$ and $13 v$ of Emery and Dewar [1982]), the phase speeds with no advective effects at $32^{\circ} \mathrm{N}, 35^{\circ} \mathrm{N}$, and $38^{\circ} \mathrm{N}$ are $-3.9 \mathrm{~cm} \mathrm{~s}^{-1}$, $-3.2 \mathrm{~cm} \mathrm{~s}^{-1}$, and $-2.7 \mathrm{~cm} \mathrm{~s}^{-1}$, respectively. This simple estimation seems to explain the propagation speed found in our northern subregions but overestimates (underestimates) the values found in the Kuroshio Extension (the southern) subregions.

Including the mean flow in (7) has two effects: First, the baroclinic shear in the mean flow $\left(U_{1}-U_{2}\right)$, which is positive in western boundary current extensions, weakens the westward propagation, and second, the mean flow of the deep circulation enhances the westward propagation when $U_{2}<0$. Based on 2-year mooring observations at a 4000$\mathrm{m}$ depth along $152^{\circ} \mathrm{E}$ and $165^{\circ} \mathrm{E}$, Schmitz [1988] and Joyce and Schmitz [1988] found that the mean zonal flows between $30^{\circ} \mathrm{N}$ and $40^{\circ} \mathrm{N}$ are both westward with a magnitude of 3 $\mathrm{cm} \mathrm{s}^{-1}\left(1 \mathrm{~cm} \mathrm{~s}^{-1}\right)$ on the southern (northern) side of $35^{\circ} \mathrm{N}$. Since the baroclinic shear effect is expected to be small outside the Kuroshio Extension, this westward deep mean flow possibly accounts for the larger westward propagation speed observed in the subregions of $30^{\circ}-34^{\circ} \mathrm{N}$ (Figure $8 \mathrm{c}$ ). Inside the Kuroshio Extension band, the vertical shear effect is no longer negligible. Using the mean values of Joyce and $S c h m i t z$ [1988] along $152^{\circ} \mathrm{E}$ and $165^{\circ} \mathrm{E}$ to represent $U_{2}$ in the upstream and downstream subregions, respectively, we estimated that a baroclinic shear exceeding $30 \mathrm{~cm} \mathrm{~s}^{-1}$ would reverse the sign of the phase speed in the upstream Kuroshio Extension region and that a baroclinic shear of about 13 $\mathrm{cm} \mathrm{s}^{-1}$ would be required for the phase speed to match the observations in the downstream subregion. Both of these estimates for the baroclinic shear values are within the range of realistic values for the Kuroshio Extension. Although there are questions about possible interannual variations in the deep mean flows and whether the mean current values at $152^{\circ} \mathrm{E}$ and $165^{\circ} \mathrm{E}$ are representative of the upstream and downstream subregions, we conclude that the effect of the mean flow is also an essential factor in the propagation of mesoscale fluctuations in the Kuroshio Extension region.

\subsection{Annual Variations in the Sea Level Difference Across the} Kuroshio Extension

Annual variations in the subtropical gyre of the North Pacific have been studied mostly for the Kuroshio through the Tokara Strait $\left(30^{\circ} \mathrm{N}, 130^{\circ} \mathrm{E}\right)$ based on tide gage observations. By analyzing the monthly sea level difference data across the Tokara Strait for 1963-1974, Blaha and Reed [1982] found that maximum Kuroshio transport is in summer, with the peak value appearing in July. Using a longer time series of sea level difference data, Kawabe [1988] studied seasonal and interannual variability of the Kuroshio at the Tokara Strait. In seasonal variations, he found a similar tendency for the sea level difference to increase in summer, followed by an abrupt decrease in September and October. More recently, Greatbatch and Goulding [1989] obtained this seasonal variation of the upstream Kuroshio in their numerical model calculations.

In the present study we determined the annual variation of the Kuroshio Extension by fitting the 2.5-year time series of the surface height difference across the stream $(\delta h)$ to a cosine wave with an annual frequency. In Figure 9, we plot-
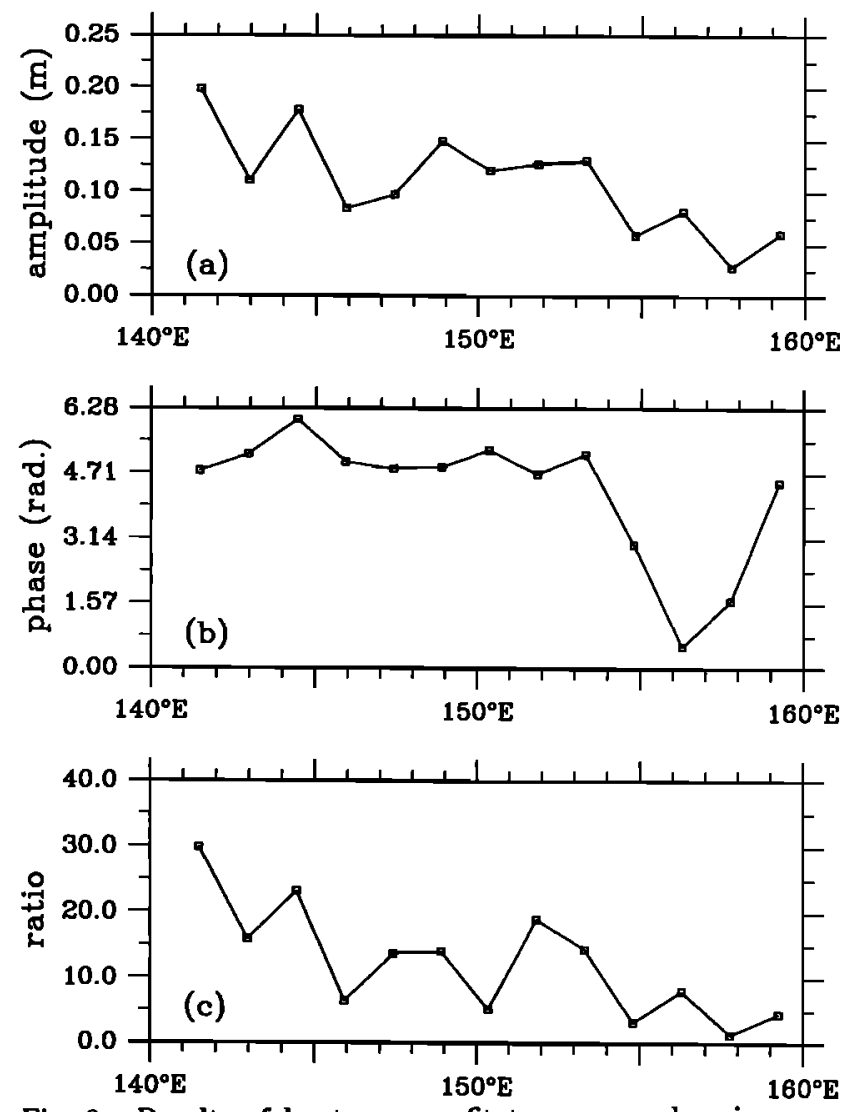

Fig. 9. Results of least squares fit to an annual cosine wave, $A \cos \left(2 \pi t / T_{0}+\theta\right)$, for the time series of surface height difference $\delta h$, where $T_{0}=365$ days: (a) amplitude $A,(b)$ phase $\theta$, and (c) percentage of variance contained in the annual signal. 
ted the amplitude, the phase, and the percentage of variance contained in the seasonal variation as a function of longitude from the least squares fit. The annual signal is significant only in the upstream region of the Kuroshio Extension (east of $154^{\circ} \mathrm{E}$ ). In this region, the seasonal variation has a nearly constant phase, an amplitude in the range of 0.1 to $0.2 \mathrm{~m}$, and is about $15 \%$ of the total $\delta h$ variance. Downstream of $154^{\circ} \mathrm{E}$, the seasonal variation appears no longer significant in terms of both its small amplitude and the small percentage of variance it accounts for. Moreover, no consistent phase values are obtained in the downstream portion of the Kuroshio Extension.

The nearly constant phase value of 5.1 radians (Figure $9 b$ ) indicates that the maximum surface height difference across the Kuroshio Extension occurs around middle or late September. This phase value corresponds well to the recent study by Zlotnicki [1991], who calculated the annual variation using the surface height difference data from Geosat averaged over a 10 -degree band $\left(143^{\circ}-152^{\circ} \mathrm{E}\right)$ across the Kuroshio Extension. Using the first year of Geosat data, Tai [1990] calculated the mean surface height differences for the four seasons. Again, fall was found to be the season with largest surface height differences across the Kuroshio Extension. Note that the maximum annual surface height difference in the Kuroshio Extension region occurs about 2 months later than in the Kuroshio, upstream at Tokara Strait [Blaha and Reed, 1982; Kawabe, 1988]. This phase lag is similar to that for the Gulf Stream system, in which the sea level difference across the Florida Strait attains its maximum in June [Niiler and Richardson, 1973], whereas the surface height difference across the Gulf Stream itself is maximum in autumn [Kelly, 1991; Zlotnicki, 1991]. Finally, it is worth mentioning that the annual signal in $\delta h$ derived about was based on the 2.5 years of data. Future long-term observations are required to reach a firmer conclusion on the annual signal of the Kuroshio Extension.

\subsection{Interannual Variations in the Axis Position and the} Surface Height Difference Across the Kuroshio Extension

In Figure 10 we present the basic statistics for the axis of the Kuroshio Extension: the mean position (solid line), the standard deviation (dashed lines), and the extreme positions (dotted lines) in the Geosat ERM period of November 1986 to April 1989. Features of the mean position are generally the same as those in the mean surface height field (Figure 3 ). The two quasi-stationary meanders, as shown by the dotted line in Figure 10, may occasionally reach as far northeast as $39^{\circ} \mathrm{N}$. There is a discernible increase in the standard deviation of position downstream of $168^{\circ} \mathrm{E}$, a fact that may be related to the existence of the Emperor Seamounts at $170^{\circ} \mathrm{E}$.

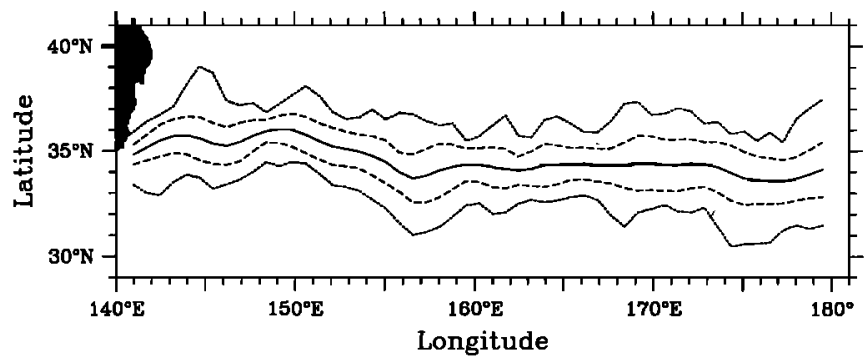

Fig. 10. The mean position (solid line), the standard deviation (dashed lines), and the extreme locations of the Kuroshio Extension axis during the Geosat ERM period of November 1986 to April 1989.
To examine the Kuroshio Extension path variations, we decomposed the time series of the axis positions into empirical or thogonal functions (EOF). The first EOF, which accounts for $23.2 \%$ of the total variance, is shown in Figure 11. Although small-scale fluctuations are also present, the spatial structure of the first EOF has a single sign and represents the large-scale coherent pattern of the Kuroshio Extension. This structure, when combined with the amplitude function (Figure 11b), indicates that the Kuroshio Extension as a whole migrated northward during the first 2 years of the Geosat period. A linear regression on the first 2 years' data shows that the speed of the northward migration is in the order of $0.1 \mathrm{~km} \mathrm{~d}^{-1}$. After fall 1988 the large-scale migration of the Kuroshio Extension reversed to southward.
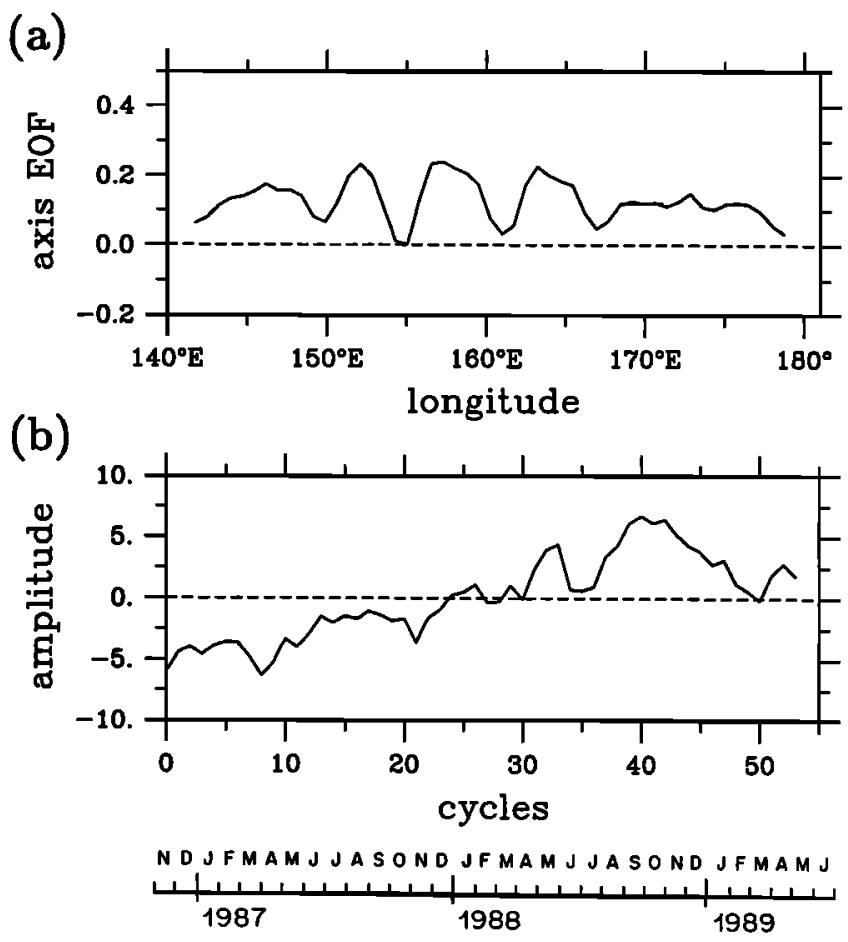

Fig. 11. The first empirical orthorgonal function of the axis position of the Kuroshio Extension (23.2\% of the total variance): (a) spatial pattern and (b) temporal amplitude. The positions have been normalized by the standard deviation at each location, so that the position variance has unit amplitude everywhere.

Large-scale, low-frequency variations in the axis position of the Gulf Stream have been shown by Kelly [1991] to correlate with the variations in the surface height difference across the Gulf Stream. To see if a similar correlation exists in the Kuroshio Extension, we compared deviations of the axis location with those of the surface height difference $(\delta h)$. To reduce small-scale wavelike signals, we zonally averaged these two time series, and the results are shown in Figure 12. Not surprisingly, the zonally averaged deviations of the axis position (solid line in Figure 12) revealed an interannual signal similar to that found using the EOF decomposition (compare Figure 11). From Figure 12, the linear trend of the Kuroshio Extension axis to migrate northward in the first 2-year period is clearly accompanied by an increase in the surface height difference across the Kuroshio Extension (dashed line, $0.15 \mathrm{~m}$ in amplitude). The two time series have a maximum cross-correlation coefficient of 0.64 , with the variation of position leading that of $\delta h$ by 17 days. For 8 degrees of freedom in the time series, this coefficient value 


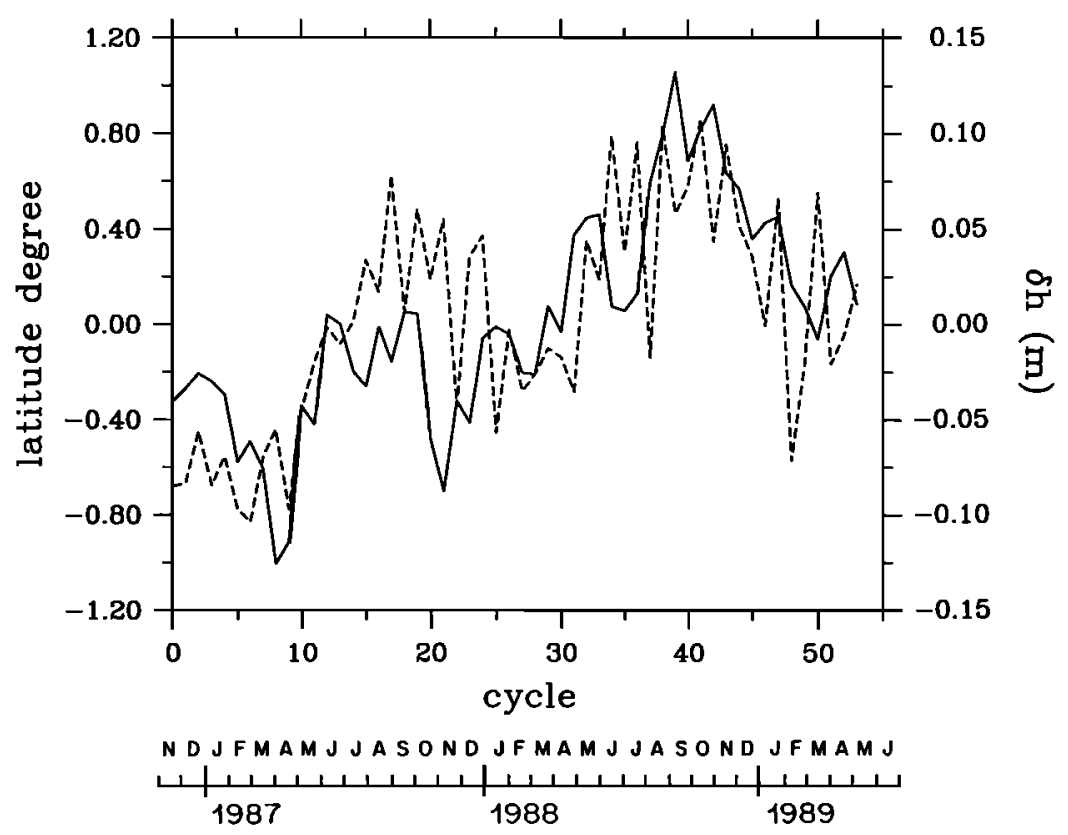

Fig. 12. Time series of the deviations of the axis position (solid line) and the surface height difference across the Kuroshio Extension (dashed line) from their respective means (compare solid lines in Figures 4 and 10). The values shown in the figure are zonally averaged from $141^{\circ} \mathrm{E}$ to $180^{\circ}$.

is significant at the $90 \%$ confidence level. The value of 17 days for the time lag, however, is not statistically significant because this is the temporal resolution of the Geosat data. Although no linear trends were apparent in the Gulf Stream, the positive correlation between the low-frequency, large-scale variations in the surface height difference and those of the current axis position is in agreement with the result found in the Gulf Stream [Kelly, 1991].

The 2.5-year time series of Geosat data is too short to ascertain the cause for the interannual signal found in Figure 12. Nevertheless, some speculations can be made based on previous relevant studies. On the basis of hydrographic and surface wind data in the western North Pacific, Qiu and Joyce [1991] have found that the strength of the negative wind stress curl field over the North Pacific intensifies during El Niño-Southern Oscillation (ENSO) events, consequently causing an increase in the transport of the North Equatorial Current (also see Wyrtki [1975b]). The last ENSO event started in late 1986 as the atmospheric convection increased in the equatorial Pacific near the date line [Kousky and Leetmaa, 1989]. Warm conditions remained in the tropical Pacific throughout 1987 and returned rapidly to normal late in the year. As is typical in other ENSO events, the transport of the North Equatorial Current was large in 1986 and 1987 and dropped significantly in 1988 [Qiu and Joyce, 1991]. On the basis of water temperature data from 1950 to 1970, Yamagata et al. [1985] showed that the intensity of the Kuroshio Extension (measured by the water temperature gradient) had a significant positive correlation with that of the North Equatorial Current at a time lag of 1.5 years. Their finding suggests that the 1986-1987 ENSO event may account for the linear increase in the $\delta h$ across the Kuroshio Extension in 1987-1988 (Figure 12).

\section{Summary and Conclusions}

On the basis of the first 2.5 years of data from the Geosat Exact Repeat Mission, we estimated the absolute surface velocity fields and investigated in detail the mean flow and temporal and spatial variability of the Kuroshio Extension in the region of $141^{\circ}-180^{\circ} \mathrm{E}$ and $30^{\circ}-40^{\circ} \mathrm{N}$.

The study first concentrated on estimating the twodimensional mean surface height field in the Kuroshio Extension region. Lack of accurate geoid information prevented us from obtaining this field directly from the surface height measurement of the Geosat ERM. The mean surface height field was derived in the present study by first calculating the synthetic mean height profiles for individual subtracks using the method of Kelly and Gille [1990]. This method estimates the alongtrack mean height profile by minimizing differences between the synthetic height data and the data of residual height plus the synthetic mean height. To achieve more efficiency and accuracy, the LevenbergMarquardt method was used in the present study tor the nonlinear parameter fitting process of the synthetic method. From the mean surface height profiles along ascending and descending subtracks, the two-dimensional mean surface height field was then solved as an inverse problem by minimizing the height difference at crossover points. Large-scale motions, such as possible recirculation gyres, were also taken into account in the height field determination.

The mean surface height pattern thus estimated is found to be in good agreement with the climatological mean of the dynamic height field from hydrographic data [Teague et al., 1990]. Differences in height jump across the Kuroshio Extension between the two results are possibly due to (1) the different spatial resolution of the Geosat measurement and a $1^{\circ}$ average of the hydrographic data and (2) the shallow reference level (1000 dbar) used in the dynamical calculation.

The success of the present study in determining the mean surface height field from the residual height data relied on the large lateral fluctuations of the Kuroshio Extension [Kelly and Gille, 1990]. This method is applicable to other ocean regions where lateral excursions of a current are comparable to the current's width. It is worth mentioning that the functional form for the current, which has been assumed 
to be Gaussian for the Gulf Stream and the Kuroshio Extension, can be chosen arbitrarily. For a more complicated current system, the nonlinear parameter fitting, though more elaborate, can be tackled using the Levenberg-Marquardt procedure.

On the basis of the mean surface height field derived above, time series of instantaneous surface height fields were estimated using the objective analysis. The results were discussed and compared with the available AVHRR images from Febuary to May 1987. Despite the rapid changes in the Kuroshio Extension during this 3-month period, the estimated instantaneous height fields were found to capture well the detailed variations of the Kuroshio Extension.

After establishing good agreement between the present study and other independent data, we analyzed the time series of the 2.5-year surface height data. The main results from the present investigation are summerized as follows:

1. In the upstream Kuroshio Extension, a stable feature is the appearance of two quasi-stationary meanders. The mean positions of the meander ridges are at $144^{\circ} \mathrm{E}$ and $149^{\circ} \mathrm{E}$ at $36^{\circ} \mathrm{N}$, though their northward excursion may occasionally reach as far as $38^{\circ} \mathrm{N}$. Maxima in the surface height difference and the mean and eddy kinetic energies (EKE and MKE) appear in the region between these two meanders.

2. East of $150^{\circ} \mathrm{E}$, the Kuroshio Extension path gradually broadens toward the southeast, resulting in a local minimum in the mean surface height difference and the MKE values along the Kuroshio Extension. The other two large drops in the mean surface height difference across the Kuroshio Extension occur east of the Shatsky Rise and the Emperor Seamounts. Since the decrease in the height difference east of the longitude $150^{\circ} \mathrm{E}$ is basically associated with the southward deflection of the height contours, these drops may reflect the confinement of recirculation gyres by large topographic features. Away from the inflow region near the coast of Japan, the ratio of EKE/M KE averaged across the Kuroshio Extension has a nearly constant value of 1.5-2.0.

3. Propagation in the surface height fluctuations was determined by separating the signals into those associated with the meandering Kuroshio Extension and those that are not. The speed was found to depend not only on latitude, but also on the downstream distance. We found that the difference in propagation speed of long baroclinic Rossby waves due to latitude change cannot fully explain the observations. On the basis of recent long-term mooring observations along $152^{\circ} \mathrm{E}$ and $165^{\circ} \mathrm{E}$, we showed that the observed deep mean flow increases the westward propagation for height fluctuations on the southern side of the Kuroshio Extension, and that the baroclinic shear is responsible for causing the fluctuations in the upstream Kuroshio Extension region to be stationary or eastward and for decreasing the westward propagation speed in the downstream Kuroshio Extension.

4. Annual variations in the sea surface height difference across the Kuroshio Extension were found to be significant in the upstream region $\left(141^{\circ}-153^{\circ} \mathrm{E}\right)$. The annual signal peaks in middle or late September with an average amplitude of 0.2 $m$. This maximum surface height difference in the Kuroshio Extension lags by 2 months the maximum sea level difference at Tokara Strait, across which the upstream Kuroshio passes. On average, the annual variation in the Kuroshio Extension explains $15 \%$ of the variance in the total fluctuations of the surface height difference.

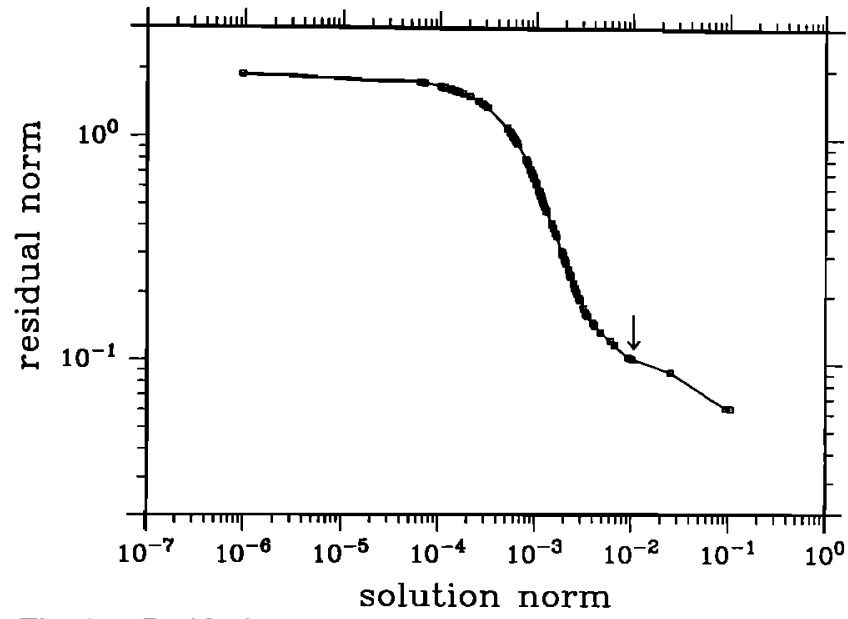

Fig. A1. Residual norm versus the solution norm for the overdetermined system of (5). The square marks in the figure indicate solutions with different ranks. The optimal solution chosen for the present study corresponds to rank $k=148$, indicated in the figure by an arrow.

5. Interannual variation is a significant signal (23\% of the total variance) in the large-scale fluctuations of the Kuroshio Extension axis position. In the first 2 years of the Geosat ERM (November 1986 to October 1988), the Kuroshio Extension as a whole shifted steadily northward with an average speed of $0.1 \mathrm{~km} \mathrm{~d}^{-1}$. This trend reversed during the following 6 months. A similar large-scale interannual variation also exists in the surface height difference across the Kuroshio Extension. The correlation between these two large-scale fluctuations is positive and statistically significant. The steady increase in the surface height difference across the Kuroshio Extension during the first twoyear period is possibly caused by the intensification of the subtropical wind gyre associated with the 1986-1987 ENSO event.

\section{APPENDIX}

The solution to the weighted equations of (5) was determined by using the singular value decomposition (SVD). As is discussed in detail by Wursch [1978] and Joyce et al. [1986], this method enables one to control the solution magnitude against the problem residual and is thus particularly useful for a linear system that has rank-deficiency. In Figure $A 1$ we show the residual norm versus the solution norm for the linear system of (5). In the figure, squares correspond to different solutions of the system. As indicated by an arrow in the figure, an optimum choice for the solution is when $k=148$, beyond which residual norm decreases slowly compared to the increase in the solution norm. Notice that $k=148$ is close to the full rank value of 153 . Investigating the SVD solutions further revealed that the eigenvalues dropped sharply beyond $k=148$, implying that the extra five parameters were not independently solved by the system. These parameters corresponded to the slopes near the two ends of the region where there were only two crossover points.

Acknowledgments. This study benefited from many discussions with Sarah Gille, Shiro Imawaki, Bill Schmitz, and Ichiro Yasuda. Mindy Hall's careful reading of the manuscript and her comments were particularly helpful. We are also grateful to William Teague for providing the dynamic height map of Figure 3b, to Mike Caruso for his technical help, and to Seiichi Saito for 
his help in providing the AVHRR images from Japan Weather Association. This work was supported by grants from NASA (NAGW-1666, K.A.K.), the NSF (OCE89-9908, T.M.J.), and by Woods Hole Oceanographic Institution (B.Q.). WHOI contribution 7649 .

\section{REFERENCES}

Bernstein, R.L., and W.B. White, Stationary and traveling mesoscale perturbations in the Kuroshio Extension current, $J$. Phys. Oceanogr., 11, 672-704, 1981.

Blaha, J., and R. Reed, Fluctuations of sea level in the western North Pacific and inferred flow of the Kuroshio, J. Phys. Oceanogr., 12, 669-678, 1982.

Caruso, M.J., Z. Sirkes, P.J. Flament, and M.K. Baker, Altimeter processing tools for analyzing mesoscale ocean features, Tech. Rep., WHOI-90-45, Woods Hole Oceanogr. Inst., Woods Hole, Mass., 1990.

Cheney, R.E., B.C. Douglas, R.W. Agreen, L. Miller, D.L. Porter, and N.S. Doyle, Geosat altimeter geophysical data record-User handbook, NOAA Tech. Memo. NOS-NGS-46, Natl. Geod. Surv., Natl. Ocean Serv., Rockville, Md., 32 pp., 1987.

Emery, W.J., and J.S. Dewar, Mean temperature-salinity, salinity-depth and temperature-depth curves for the North Atlantic and the North Pacific, Prog. Oceanogr., 11, 219-305, 1982.

Greatbatch, R.J., and A. Goulding, Seasonal variations in a linear barotropic model of the North Pacific driven by Hellerman and Rosenstein wind stress field, J. Geophys. Res., 94, 12,64512,665, 1989.

Hall, M.M., Velocity and transport structure of the Kuroshio Extension at $35^{\circ} \mathrm{N}, 152^{\circ} \mathrm{E}, J$. Geophys. Res., 94, 14,445-14,459, 1989.

Hall, M.M., Energetics of the Kuroshio Extension at $35^{\circ} \mathrm{N}, 152^{\circ} \mathrm{E}$, J. Phys. Oceanogr., 21, 958-975, 1991.

Hall, M.M., and H.L. Bryden, Profiling the Gulf Stream with a current meter mooring, Geophys. Res. Lett., 12, 203-206, 1985.

Imawaki, S., K. Ichikawa, and H. Nishigaki, Estimating mean seasurface elevation field from satellite altimetry data by optima interpolation, J. Geophys. Res., in press, 1991.

Joyce, T.M., Hydrographic sections across the Kuroshio Extension at $165^{\circ} \mathrm{E}$ and $175^{\circ} \mathrm{W}$, Deep Sea Res., 34, 1331-1352, 1987.

Joyce T.M., and W.J. Schmitz, Jr., Zonal velocity structure and transport in the Kuroshio Extension, J. Phys. Oceanogr., 18, 1484-1494, 1988.

Joyce, T.M., C. Wunsch, and S.D. Pierce, Synoptic Gulf Stream velocity profiles through simultaneous inversion of hydrographic and acoustic Doppler data, J. Geophys. Res., 91, 75737585, 1986.

Joyce, T.M., K.A. Kelly, D.M. Schubert, and M.J. Caruso, Shipboard and altimetric studies of rapid Gulf Stream variability between Cape Cod and Bermuda, Deep Sea Res., 37, 879-910, 1990.

Kawai, H., Hydrography of the Kuroshio Extension, in KuroshioIts Physical Aspects, edited by $\mathrm{H}$. Stommel and K. Yoshida, pp. 235-354, University of Tokyo Press, Tokyo, 1972.

Kawa, H., and S. Saitoh, Secondary fronts, warm tongues and warm streamers of the Kuroshio Extension system, Deep Sea Res., 99, 1487-1507, 1986.

Kawabe, M., Sea level variations at the Izu Islands and typical stable paths of the Kuroshio, J. Oceanogr. Soc. Jpn., 41, 307$326,1985$.

Kawabe, M., Variability of Kuroshio velocity assessed from the sea-level difference between Naze and Nishinoomote, $J$. Oceanogr. Soc. Jpn., 44, 293-304, 1988.

Kawamura, H., K. Mizuno, and Y. Toba, Formation process of a warm-core ring in the Kuroshio-Oyashio frontal zoneDecember 1982-October 1982, Deep Sea Res., 99, 1617-1640, 1986.

Kelly, K.A., The meandering Gulf Stream as seen by the Geosat altimeter: Surface transport, position, and velocity variance from $73^{\circ}$ to $46^{\circ} \mathrm{W}, J$. Geophys. Res., in press, 1991.

Kelly, K.A., and S.T. Gille, Gulf Stream surface transport and statistics at $69^{\circ} \mathrm{W}$ from the Geosat altimeter, J. Geophys. Res., 95, 3149-3161, 1990.

Kelly, K.A., T.M. Joyce, D.M. Schubert, and M.J. Caruso, The mean sea surface height and geoid along the Geosat subtrack from Bermuda to Cape Cod, J. Geophys. Res., 96, 12,69912,709, 1991.

Kousky, V.E., and A. Leetmaa, The 1986-87 Pacific warm episode: Evolution of oceanic and atmospheric anomaly fields, J. Clim., 2, 254-267, 1989.

Levitus, S., Climatological Atlas of the World Ocean, NOAA Prof. Pap. 19, 173 pp., U.S. Government Printing Office, Washington, D.C., 1982.

Marsh, J.G., and E.S. Chang, 5' detailed gravimetric geoid in the northwestern Atlantic Ocean, Mar. Geod., 1, 253-261, 1984.

Masuzawa, J., Water characteristics of the North Pacific central region, in Kuroshio-Its Physical A spects, edited by H. Stommel and K. Yoshida, pp.95-128, University of Tokyo Press, Tokyo, 1972.

Mizuno, K., and W.B. White, Annual and interannual variability in the Kuroshio Current system, J. Phys. Oceanogr., 13, 18471867, 1983.

Niiler, P.P., and W. S. Richardson, Seasonal variability of the Florida Current, J. Mar. Res., s1, 144-167, 1973.

Niiler, P.P., W.J. Schmitz, Jr., and D.K. Lee, Geostrophic volume transport in high eddy-energy areas of the Kuroshio Extension and the Gulf Stream, J. Phys. Oceanogr., 15, 825-843, 1985.

Nishida, H., and W.B. White, Horizontal eddy fluxes of momentum and kinetic energy in the near-surface of the Kuroshio Extension, J. Phys. Oceanogr., 12, 160-170, 1982.

Pedlosky, J., Geophysical Fluid Dynamics, 624 pp., SpringerVerlag, New York, 1979.

Press, W.H., B.P. Flannery, S.A. Teukolsky, and W.T. Vetterling, Numerical Recipes, 818 pp., Cambridge University Press, New York, 1986.

Qiu, B., and T.M. Joyce, Interannual variability in the midand low-latitude western North Pacific, J. Phys. Oceanogr., in press, 1991.

Schmitz, W.J.,Jr., Exploration of the eddy field in the midlatitude North Pacific, J. Phys. Oceanogr., 18, 459-468, 1988.

Schmitz, W.J., Jr., and W.R. Holland, Observed and modeled mesoscale variability near the Gulf Stream and Kuroshio Extension, J. Geophys. Res., 91, 9624-9638, 1986.

Schmitz, W.J., Jr., P.P. Niiler, R.L. Bernstein, and W.R. Holland, Recent long-term moored instrument observations in the western North Pacific, J. Geophys. Res., 87, 9425-9440, 1982.

Schmitz, W.J., Jr., P.P. Niiler, and C.J. Koblinsky, Two-year moored instrument results along $152^{\circ} \mathrm{E}, J$. Geophys. Res., 92, 10,826-10,834, 1987.

Tai, C.-T., Estimating the surface transport of meandering oceanic jet streams from satellite altimetry: Surface transport estimates for the Gulf Stream and Kuroshio Extension, J. Phys. Oceanogr., 20, 860-879, 1990.

Tai, C.-T., and W.B. White, Eddy variability in the Kuroshio Extension as revealed by Geosat altimetry: Energy propagation away from the jet, Reynolds stress, and seasonal cycle, J. Phys. Oceanogr., 20, 1761-1777, 1990.

Tai, C.K., and C. Wunsch, An estimate of global absolute dynamic topography, J. Phys. Oceanogr., 14, 457-463, 1984.

Teague, W.J., M.J. Carron, and P.J. Hogan, A comparison between the Generalized Digital Environmental Model and Levitus climatologies, J. Geophys. Res., 95, 7167-7183, 1990.

Wunsch, C., The North Atlantic general circulation west of $50^{\circ} \mathrm{N}$ determined by inverse methods, Rev. Geophys., 16, 583-620, 1978.

Wunsch, C., and E.M. Gaposchkin, On using satellite altimetry to determine the general circulation of the oceans with application to geoid improvement, Rev. Geophys., 18, 728-745, 1980.

Wunsch, C., D.-X. Hu, and B. Grant, Mass, heat, salt and nutrient fluxes in the South Pacific Ocean, J. Phys. Oceanogr., 13, 725-753, 1983.

Wyrtki, K., Fluctuations of the dynamic topography in the $\mathrm{Pa}$ cific Ocean, J. Phys. Oceanogr., 5, 450-459, 1975 a.

Wyrtki, K., El Niño-The dynamic response of the equatorial $\mathrm{Pa}$ cific Ocean to atmospheric forcing, J. Phys. Oceanogr., 5, 572584,19756 .

Yamagata, T., Y. Shibao, and S. Umatani, Interannual variability of the Kuroshio Extension and its relation to the Southern Oscillation/E1 Niño, J. Oceanogr. Soc. Jpn., 41, 274-281, 1985. 
Yasuda, I., K. Okuda, and K. Mizuno, Numerical study on the vortices near boundaries-Considerations on warm core rings in the vicinity of east coast of Japan, Bull. Tohoku Reg. Fish. Res. Lab., 48, 67-86, 1986.

Yasuda, I., K. Okuda, and M. Hirai, Evolution of a Kuroshio warm-core ring-Variability of the hydrographic structure, Deep Sea Res., in press, 1991.

Zlotnicki, V., Sea level differences across the Gulf Stream and
Kuroshio Extension, J. Phys. Oceanogr., 21, 599-609, 1991.

T.M. Joyce, K.A. Kelly, and B. Qiu, Woods Hole Oceanographic Institution, Woods Hole, MA 02543.

(Received February 7, 1991;
revised June 19, 1991;

accepted June 24, 1991.) 